\title{
De Novo Tailoring Pore Morphologies and Sizes for Different Substrates in a Urea-Containing MOFs Catalytic Platform
}

\author{
Zhanfeng Ju, ${ }^{\dagger}$ Shichen Yan, ${ }^{\dagger, \ddagger}$ and Daqiang Yuan*, ${ }^{*}$
}

'State Key Laboratory of Structural Chemistry, Fujian Institute of Research on the Structure of Matter, Chinese Academy of Sciences, Fuzhou, 350002, China, E-mail: ydq@fjirsm.ac.cn

${ }^{\ddagger}$ College of Chemistry, Fuzhou University, Fuzhou, 350002, China

\section{Supporting information}

\section{Table of contents}

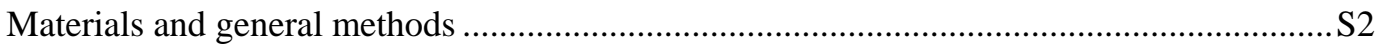

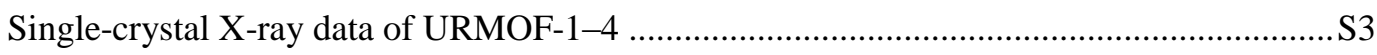

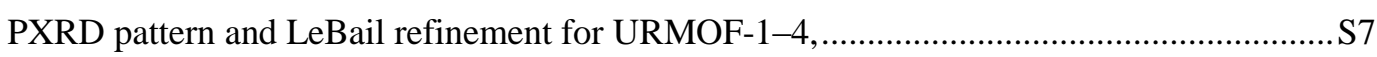

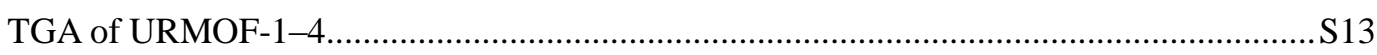

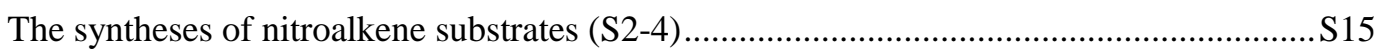

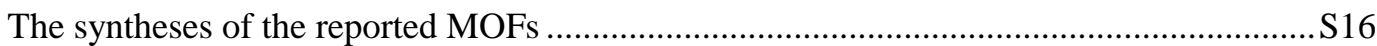

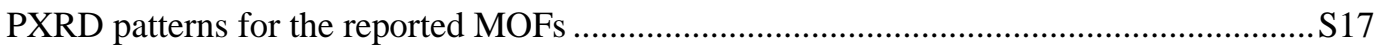

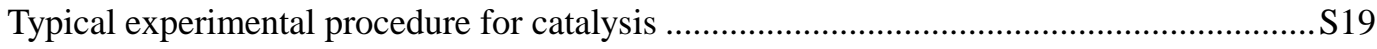

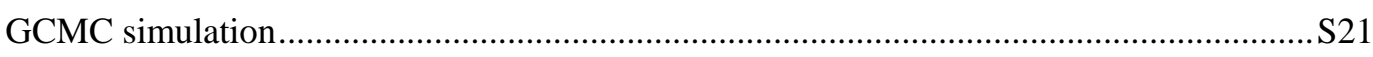

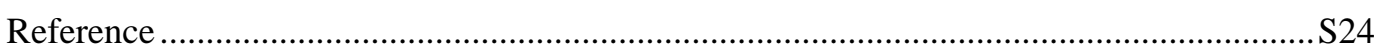

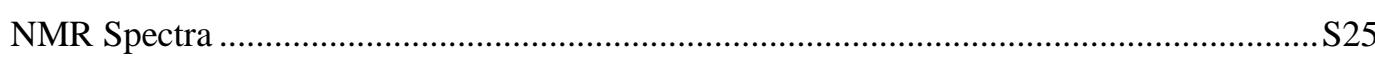




\section{Materials and general methods}

All the reagent and solvents are purchased from commercial sources. Elemental analyses for $\mathrm{C}, \mathrm{H}$ and $\mathrm{N}$ are carried out on a German Elementary Vario EL III instrument. The FT-IR spectra are performed on a Nicolet Magna 750 FT-IR. Spectrometer using $\mathrm{KBr}$ pellets in the range of $4000-400 \mathrm{~cm}^{-1}$. ${ }^{1} \mathrm{H}$ NMR spectra are obtained on a Burker AVANCE $400(400 \mathrm{MHz})$ for spectrometer and are reported in ppm using solvent as an internal standard $\left(\mathrm{CDCl}_{3}\right.$ at $7.26 \mathrm{ppm}$ and $\mathrm{DMSO}-\mathrm{d}_{6}$ at $\left.2.50 \mathrm{ppm}\right)$. Data are reported as (ap = apparent, $\mathrm{s}=$ singlet, $\mathrm{d}=$ doublet, $\mathrm{t}=$ triplet, $\mathrm{q}=$ quartet, $\mathrm{m}=$ multiplet, $\mathrm{b}=$ broad; coupling constant(s) in $\mathrm{Hz}$; integration. Proton-decoupled ${ }^{13} \mathrm{C}-\mathrm{NMR}$ spectra were recorded on an AVANCE 400 (100 MHz) spectrometer and are reported in ppm using solvent as an internal standard $\left(\mathrm{CDCl}_{3}\right.$ at $77.16 \mathrm{ppm}$ and DMSO- $\mathrm{d}_{6}$ at $\left.39.52 \mathrm{ppm}\right)$. Mass spectra data was obtained on an Agilent 1100 Series LC/MSD. Thermogravimetric analyses are recorded on a NETZSCH STA 449C unit at a heating rate of $10^{\circ} \mathrm{C} \cdot \mathrm{min}^{-1}$ under nitrogen atmosphere. The powder X-ray diffraction (PXRD) patterns are collected by a Rigaku DMAX2500 X-ray diffractometer using $\mathrm{Cu} \mathrm{K \alpha}$ radiation $(\lambda=0.154 \mathrm{~nm})$. Simulation of the PXRD spectrum are carried out by the single-crystal data and diffraction-crystal module of the Mercury program available free of charge via Internet at http://www.ccdc.cam.ac.uk/products/mercury/.

\section{Single-crystal X-ray data of URMOF-1-4}

Single-crystal X-ray data of URMOF-1-4 are collected on a SuperNova, Dual, $\mathrm{Cu}$ at zero, Atlas diffractometer. The crystal was kept at 100(1) K during data collection. The structure was solved by direct methods and refined by full-matrix least-squares on F2 with anisotropic displacement using the SHELXTL software package. ${ }^{\mathrm{S} 1}$ The non-H atoms were treated anisotropically, whereas the aromatic and hydroxy- and alkyl-hydrogen atoms were placed in calculated, ideal positions and refined as riding on their respective carbon atoms. In URMOF-1-4, free solvent molecules were highly disordered, and attempts to locate and refine the solvent peaks were unsuccessful. The diffused electron densities resulting from these residual solvent molecules were removed from the data set using the SQUEEZE routine of PLATON and refined further using the data generated. ${ }^{\text {S2 }}$ The contents of the solvent region are not represented in the unit cell contents in the crystal data. The details for data collection and refinement are included in the CIF file in the Supporting Information. Some primary crystal data were list in Table $\mathrm{S} 1-4$ as follows. Crystallographic data (excluding structure factors) for the structures reported in this paper have been deposited in the Cambridge Crystallographic Data Center with CCDC Number: 1422970 for URMOF-1, 1422971 for URMOF-2, 1422968 for URMOF-3, and 1422969 for URMOF-4. 


\section{Single-crystal X-ray data of URMOF-1-4}

Table S1. Crystal data and structure refinement for URMOF-1

\begin{tabular}{|c|c|}
\hline Identification code & URMOF-1 \\
\hline Empirical formula & $\mathrm{C}_{33} \mathrm{H}_{24} \mathrm{Cu}_{3} \mathrm{~N}_{6} \mathrm{O}_{18}$ \\
\hline Formula weight & 983.20 \\
\hline Temperature & $100(2) \mathrm{K}$ \\
\hline Wavelength & $1.54184 \AA$ \\
\hline Crystal system & Tetragonal \\
\hline Space group & I $4 / \mathrm{m}$ \\
\hline \multirow[t]{3}{*}{ Unit cell dimensions } & $a=30.4638(3) \AA \quad \alpha=90^{\circ}$ \\
\hline & $\mathrm{b}=30.4638(3) \AA \quad \beta=90^{\circ}$ \\
\hline & $\mathrm{c}=44.2772(7) \AA \quad \gamma=90^{\circ}$ \\
\hline Volume & 41091.1(10) $\AA^{3}$ \\
\hline $\mathrm{Z}$ & 16 \\
\hline Density (calculated) & $0.636 \mathrm{Mg} / \mathrm{m}^{3}$ \\
\hline Absorption coefficient & $1.009 \mathrm{~mm}^{-1}$ \\
\hline $\mathrm{F}(000)$ & 7920 \\
\hline Reflections collected & 41283 \\
\hline Independent reflections & $20219[\mathrm{R}(\mathrm{int})=0.0318]$ \\
\hline Completeness to theta $=67.684^{\circ}$ & $99.4 \%$ \\
\hline Absorption correction & Semi-empirical from equivalents \\
\hline Goodness-of-fit on $\mathrm{F}^{2}$ & 0.974 \\
\hline Final $\mathrm{R}$ indices $[\mathrm{I}>2 \operatorname{sigma}(\mathrm{I})]$ & $\mathrm{R} 1=0.0764, \mathrm{wR} 2=0.2187$ \\
\hline $\mathrm{R}$ indices (all data) & $\mathrm{R} 1=0.1083, \mathrm{wR} 2=0.2580$ \\
\hline
\end{tabular}


Table S2. Crystal data and structure refinement for URMOF-2

\begin{tabular}{|c|c|}
\hline Identification code & URMOF-2 \\
\hline Empirical formula & $\mathrm{C}_{33} \mathrm{H}_{24} \mathrm{~N}_{6} \mathrm{O}_{18} \mathrm{Zn}_{3}$ \\
\hline Formula weight & 988.69 \\
\hline Temperature & $100(2) \mathrm{K}$ \\
\hline Wavelength & $1.54184 \AA$ \\
\hline Crystal system & Tetragonal \\
\hline Space group & $\mathrm{I} 4 / \mathrm{m}$ \\
\hline \multirow[t]{3}{*}{ Unit cell dimensions } & $a=30.5919(7) \AA \quad \alpha=90^{\circ}$ \\
\hline & $\mathrm{b}=30.5919(7) \AA \quad \beta=90^{\circ}$ \\
\hline & $c=44.8181(19) \AA \quad \gamma=90^{\circ}$ \\
\hline Volume & $41944(3) \AA^{3}$ \\
\hline $\mathrm{Z}$ & 16 \\
\hline Density (calculated) & $0.626 \mathrm{Mg} / \mathrm{m}^{3}$ \\
\hline Absorption coefficient & $1.082 \mathrm{~mm}^{-1}$ \\
\hline $\mathrm{F}(000)$ & 7968 \\
\hline Reflections collected & 38997 \\
\hline Independent reflections & $20576[\mathrm{R}(\mathrm{int})=0.0397]$ \\
\hline Completeness to theta $=67.684^{\circ}$ & $99.3 \%$ \\
\hline Absorption correction & Semi-empirical from equivalents \\
\hline Goodness-of-fit on $\mathrm{F}^{2}$ & 1.034 \\
\hline Final R indices [I>2sigma(I)] & $\mathrm{R} 1=0.0931, \mathrm{wR} 2=0.2665$ \\
\hline $\mathrm{R}$ indices (all data) & $\mathrm{R} 1=0.1390, \mathrm{wR} 2=0.3265$ \\
\hline
\end{tabular}


Table S3. Crystal data and structure refinement for URMOF-3

\begin{tabular}{|c|c|}
\hline Identification code & URMOF-3 \\
\hline Empirical formula & $\mathrm{C}_{60} \mathrm{H}_{42} \mathrm{~N}_{12} \mathrm{O}_{19} \mathrm{Zn}_{4}$ \\
\hline Formula weight & 1496.53 \\
\hline Temperature & 293(2) K \\
\hline Wavelength & $1.54184 \AA$ \\
\hline Crystal system & Cubic \\
\hline Space group & $\mathrm{Pa}-3$ \\
\hline \multirow[t]{3}{*}{ Unit cell dimensions } & $a=33.9803(5) \AA \quad \alpha=90^{\circ}$ \\
\hline & $\mathrm{b}=33.9803(5) \AA \quad \beta=90^{\circ}$ \\
\hline & $\mathrm{c}=33.9803(5) \AA \quad \gamma=90^{\circ}$ \\
\hline Volume & $39235.7(17) \AA^{3}$ \\
\hline $\mathrm{Z}$ & 4 \\
\hline Density (calculated) & $0.253 \mathrm{Mg} / \mathrm{m}^{3}$ \\
\hline Absorption coefficient & $0.392 \mathrm{~mm}^{-1}$ \\
\hline $\mathrm{F}(000)$ & 3032 \\
\hline Reflections collected & 21978 \\
\hline Independent reflections & $8401[\mathrm{R}($ int $)=0.0960]$ \\
\hline Completeness to theta $=67.684^{\circ}$ & $98.5 \%$ \\
\hline Absorption correction & Semi-empirical from equivalents \\
\hline Goodness-of-fit on $\mathrm{F}^{2}$ & 1.080 \\
\hline Final $\mathrm{R}$ indices [I $>2 \operatorname{sigma}(\mathrm{I})]$ & $\mathrm{R} 1=0.1684, \mathrm{wR} 2=0.3433$ \\
\hline $\mathrm{R}$ indices (all data) & $\mathrm{R} 1=0.2716, \mathrm{wR} 2=0.3897$ \\
\hline
\end{tabular}


Table S4. Crystal data and structure refinement for URMOF-4

\begin{tabular}{|c|c|}
\hline Identification code & URMOF-4 \\
\hline Empirical formula & $\mathrm{C}_{60} \mathrm{H}_{48} \mathrm{In}_{3} \mathrm{~N}_{12} \mathrm{O}_{22}$ \\
\hline Formula weight & 1633.56 \\
\hline Temperature & 293(2) K \\
\hline Wavelength & $1.54184 \AA$ \\
\hline Crystal system & Trigonal \\
\hline Space group & P 3121 \\
\hline \multirow[t]{3}{*}{ Unit cell dimensions } & $\mathrm{a}=24.4186(5) \AA \quad \alpha=90^{\circ}$ \\
\hline & $\mathrm{b}=24.4186(5) \AA \quad \beta=90^{\circ}$ \\
\hline & $\mathrm{c}=55.4757(11) \AA \quad \gamma=120^{\circ}$ \\
\hline Volume & $28646.7(13) \AA^{3}$ \\
\hline $\mathrm{Z}$ & 3 \\
\hline Density (calculated) & $0.284 \mathrm{Mg} / \mathrm{m}^{3}$ \\
\hline Absorption coefficient & $1.562 \mathrm{~mm}^{-1}$ \\
\hline $\mathrm{F}(000)$ & 2445 \\
\hline Reflections collected & 70596 \\
\hline Independent reflections & $36370[\mathrm{R}(\mathrm{int})=0.0882]$ \\
\hline Completeness to theta $=67.684^{\circ}$ & $99.9 \%$ \\
\hline Absorption correction & Semi-empirical from equivalents \\
\hline Goodness-of-fit on $\mathrm{F}^{2}$ & 0.899 \\
\hline Final $\mathrm{R}$ indices [I $>2 \operatorname{sigma}(\mathrm{I})]$ & $\mathrm{R} 1=0.0627, \mathrm{wR} 2=0.1506$ \\
\hline $\mathrm{R}$ indices (all data) & $\mathrm{R} 1=0.1078, \mathrm{wR} 2=0.1905$ \\
\hline
\end{tabular}




\section{PXRD pattern and LeBail refinement for URMOF-1-4,}

To confirm the purity and the stability of the sample, the pattern matching analysis were carried out for URMOF-1-4 by the LeBail route. By comparing the calculated and experimental pattern, the final fit show very good agreement with the initial structure, which indicated the fresh samples are pure and all the URMOFs are stable even after $5^{\text {th }}$ cycle of catalysis experiment. The detail data are illustrated in Table S5 and the PXRD pattern are shown in Figure S1-8.

Table S5 the pattern matching analysis data for URMOF-1 by the LeBail route

\begin{tabular}{|c|c|c|c|c|}
\hline & URMOF-1 & & URMOF- $1^{p c}$ & \\
\hline Initial lattice parameter & $\begin{array}{l}\mathrm{a}=30.4638 \AA \\
\mathrm{b}=30.4638 \AA \\
\mathrm{c}=44.2772 \AA \\
\mathrm{V}=41091.1 \AA^{3}\end{array}$ & $\begin{array}{l}\alpha=90^{\circ} \\
\beta=90^{\circ} \\
\gamma=90^{\circ}\end{array}$ & $\begin{array}{l}\mathrm{a}=30.4638 \AA \\
\mathrm{b}=30.4638 \AA \\
\mathrm{c}=44.2772 \AA \\
\mathrm{V}=41091.1 \AA^{3}\end{array}$ & $\begin{array}{l}\alpha=90^{\circ} \\
\beta=90^{\circ} \\
\gamma=90^{\circ}\end{array}$ \\
\hline Fitted lattice parameter & $\begin{array}{l}\mathrm{a}=30.5570 \AA \\
\mathrm{b}=30.5570 \AA \\
\mathrm{c}=44.2806 \AA \\
\mathrm{V}=41346.2 \AA^{3}\end{array}$ & $\begin{array}{l}\alpha=90^{\circ} \\
\beta=90^{\circ} \\
\gamma=90^{\circ}\end{array}$ & $\begin{array}{l}\mathrm{a}=30.4765 \AA \\
\mathrm{b}=30.4765 \AA \\
\mathrm{c}=43.9622 \AA \\
\mathrm{V}=40832.9 \AA^{3}\end{array}$ & $\begin{array}{l}\alpha=90^{\circ} \\
\beta=90^{\circ} \\
\gamma=90^{\circ}\end{array}$ \\
\hline $\mathbf{R}_{\mathrm{B}}$ & 5.78 & & 12.10 & \\
\hline $\mathbf{R}_{\mathbf{p}}$ & 3.71 & & 8.44 & \\
\hline $\mathbf{R}_{\text {exp }}$ & 3.34 & & 5.09 & \\
\hline$\chi^{2}$ & 3.00 & & 5.65 & \\
\hline
\end{tabular}

Table S6 the pattern matching analysis data for URMOF-2 by the LeBail route

\begin{tabular}{|c|c|c|}
\hline & URMOF-2 & URMOF- $2^{p c}$ \\
\hline Initial lattice parameter & $\begin{array}{ll}a=30.5919(7) \AA & \alpha=90^{\circ} \\
b=30.5919(7) \AA & \beta=90^{\circ} \\
c=44.8181(19) \AA & \gamma=90^{\circ} \\
V=41944 \AA^{3} & \end{array}$ & $\begin{array}{ll}a=30.5919(7) \AA & \alpha=90^{\circ} \\
b=30.5919(7) \AA & \beta=90^{\circ} \\
c=44.8181(19) \AA & \gamma=90^{\circ} \\
V=41944 \AA^{3} & \end{array}$ \\
\hline Fitted lattice parameter & $\begin{array}{ll}\mathrm{a}=31.4610 \AA & \alpha=90^{\circ} \\
\mathrm{b}=31.4610 \AA & \beta=90^{\circ} \\
\mathrm{c}=44.7026 \AA & \gamma=90^{\circ} \\
\mathrm{V}=44236.4 \AA^{3} & \end{array}$ & $\begin{array}{ll}\mathrm{a}=30.6513 \AA & \alpha=90^{\circ} \\
\mathrm{b}=30.6513 \AA & \beta=90^{\circ} \\
\mathrm{c}=45.2467 \AA & \gamma=90^{\circ} \\
\mathrm{V}=42509.3 \AA^{3} & \end{array}$ \\
\hline $\mathbf{R}_{\mathrm{B}}$ & 7.63 & 8.79 \\
\hline $\mathbf{R}_{\mathrm{p}}$ & 5.56 & 5.93 \\
\hline $\mathbf{R}_{\text {exp }}$ & 4.04 & 6.58 \\
\hline
\end{tabular}




\begin{tabular}{lll}
\hline$\chi^{2}$ & 3.57 & 1.79 \\
\hline$P c$ represents post catalysis &
\end{tabular}

Table S7 the pattern matching analysis data for URMOF-3 by the LeBail route

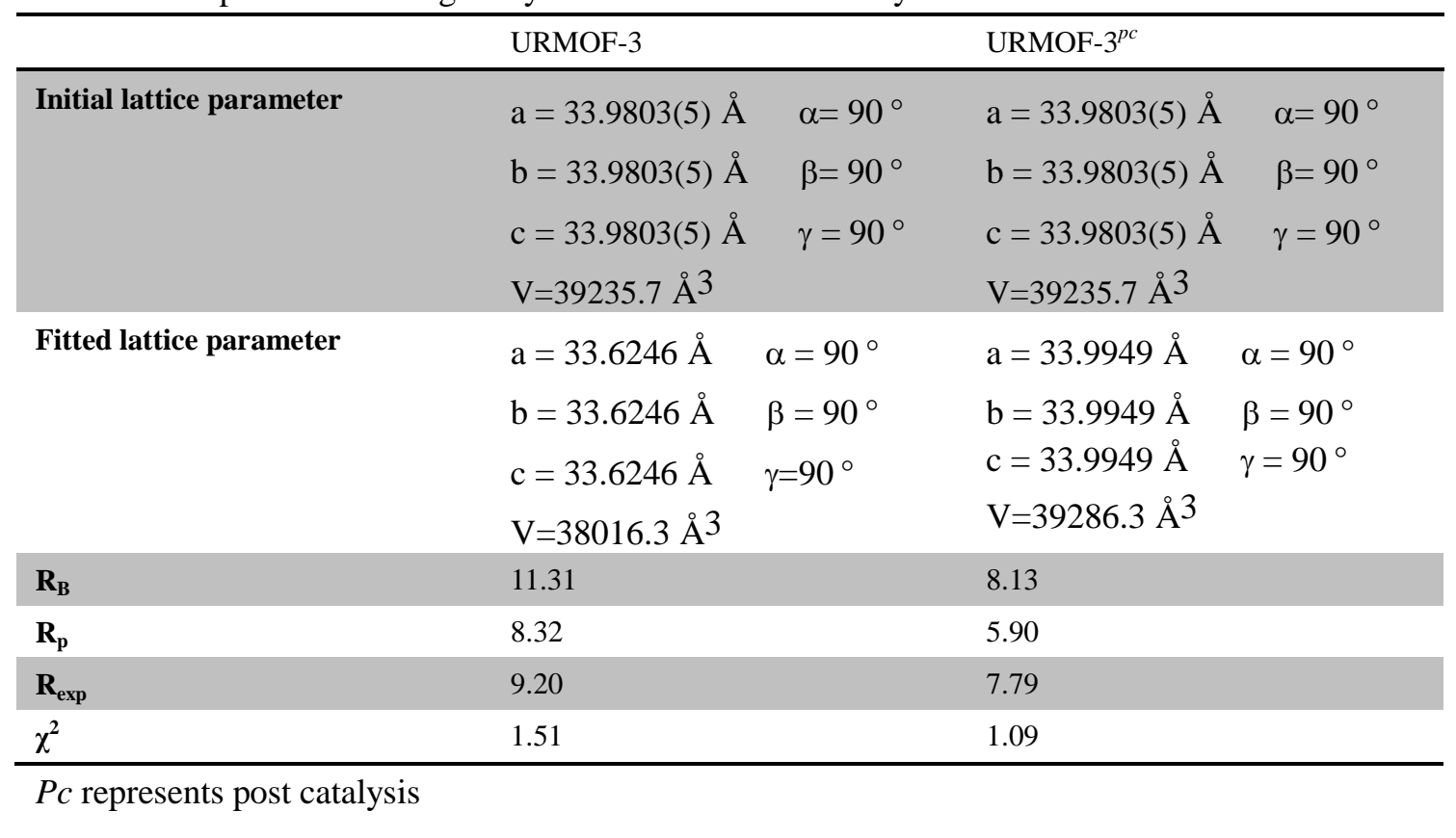

Table S8 the pattern matching analysis data for URMOF-4 by the LeBail route

\begin{tabular}{lllll}
\hline & URMOF-4 & \multicolumn{3}{l}{ URMOF-4 $^{p c}$} \\
\hline Initial lattice parameter & $\mathrm{a}=24.4186(5) \AA$ & $\alpha=90^{\circ}$ & $\mathrm{a}=24.4186(5) \AA$ & $\alpha=90^{\circ}$ \\
& $\mathrm{b}=24.4186(5) \AA$ & $\beta=90^{\circ}$ & $\mathrm{b}=24.4186(5) \AA$ & $\beta=90^{\circ}$ \\
& $\mathrm{c}=55.4757(11) \AA$ & $\gamma=120^{\circ}$ & $\mathrm{c}=55.4757(11) \AA$ & $\gamma=120^{\circ}$ \\
& $\mathrm{V}=28646.7 \AA^{3}$ & & $\mathrm{~V}=28646.7 \AA^{3}$ & \\
Fitted lattice parameter & $\mathrm{a}=24.4373 \AA$ & $\alpha=90^{\circ}$ & $\mathrm{a}=24.4282 \AA$ & $\alpha=90^{\circ}$ \\
& $\mathrm{b}=24.4373 \AA$ & $\beta=90^{\circ}$ & $\mathrm{b}=24.4282 \AA$ & $\beta=90^{\circ}$ \\
& $\mathrm{c}=55.5704 \AA$ & $\gamma=90^{\circ}$ & $\mathrm{c}=55.5038 \AA$ & $\gamma=90^{\circ}$ \\
& $\mathrm{V}=28739.6 \AA^{3}$ & & $\mathrm{~V}=28683.8 \AA^{3}$ & \\
$\mathbf{R}_{\mathbf{B}}$ & 5.80 & & 6.08 & \\
$\mathbf{R}_{\mathbf{p}}$ & 3.80 & & 4.43 & \\
$\mathbf{R}_{\text {exp }}$ & 5.17 & & 0.16 & \\
$\chi^{2}$ & 1.26 & & & \\
\hline$P c$ & & & & \\
\hline
\end{tabular}

$P c$ represents post catalysis 


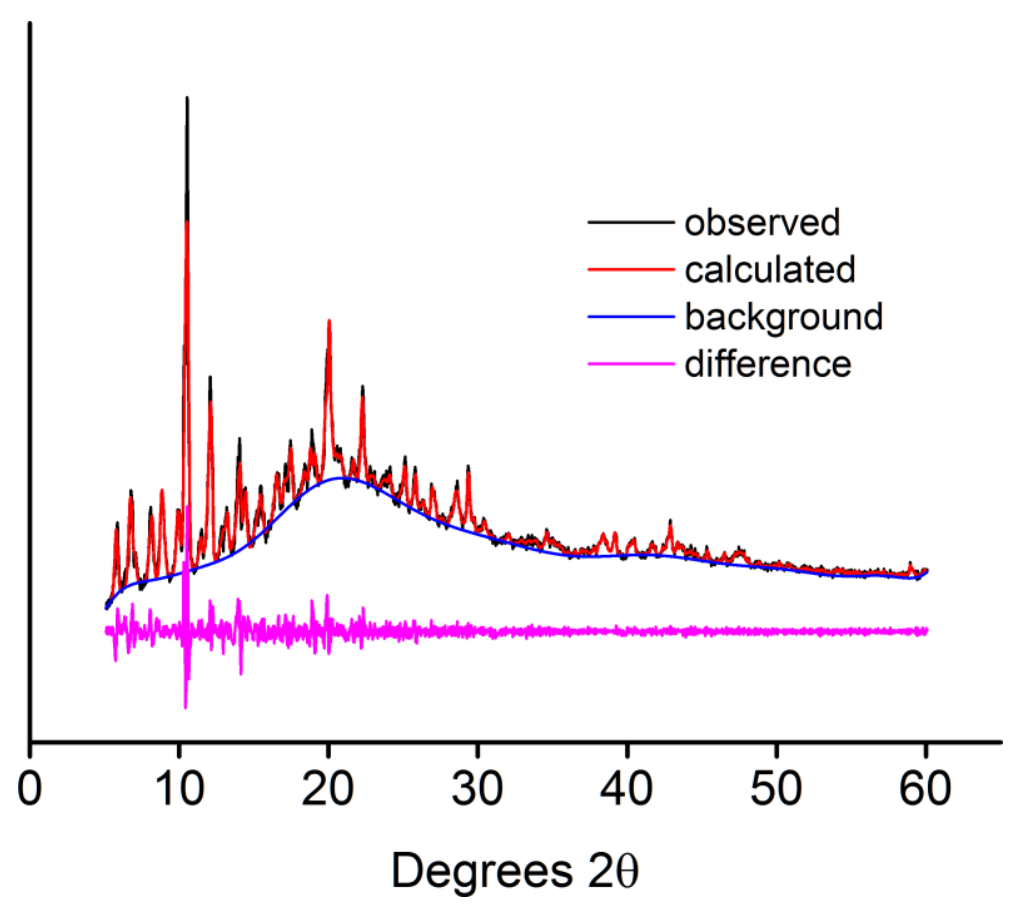

Figure S1. LeBail method fit to PXRD data for URMOF-1

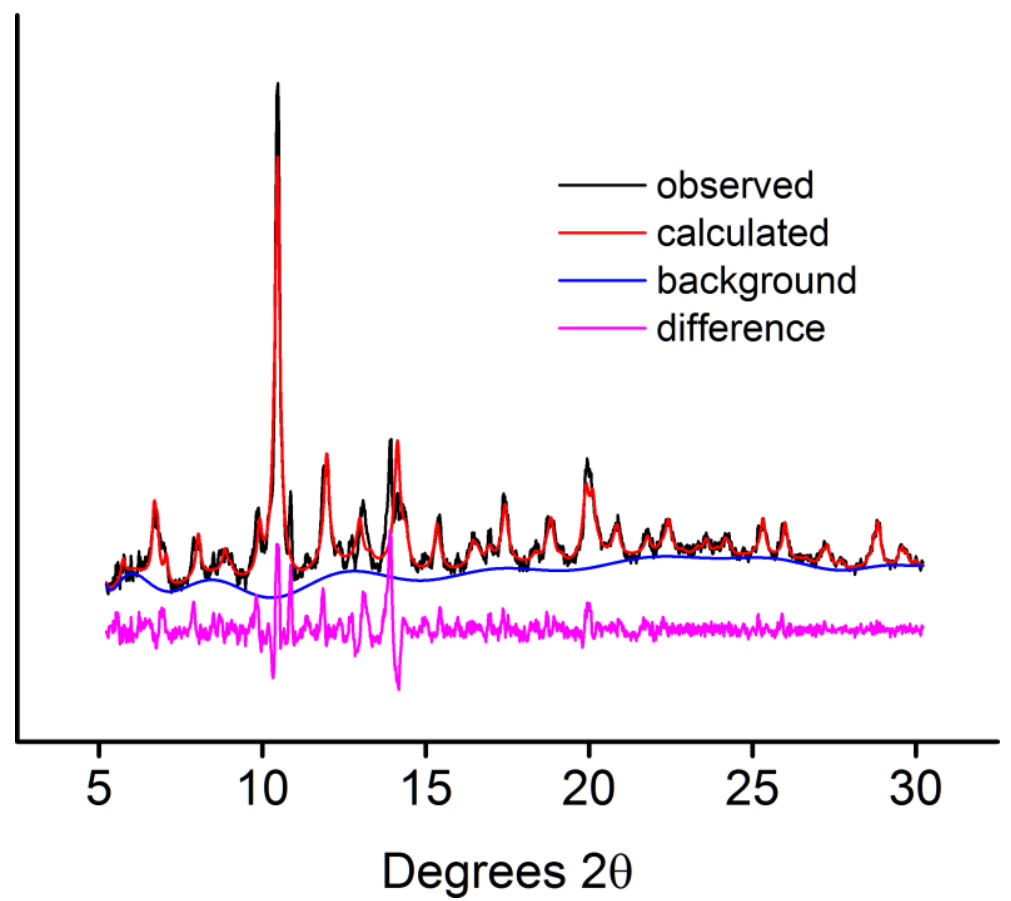

Figure S2. LeBail method fit to PXRD data for post-catalysis URMOF-1 


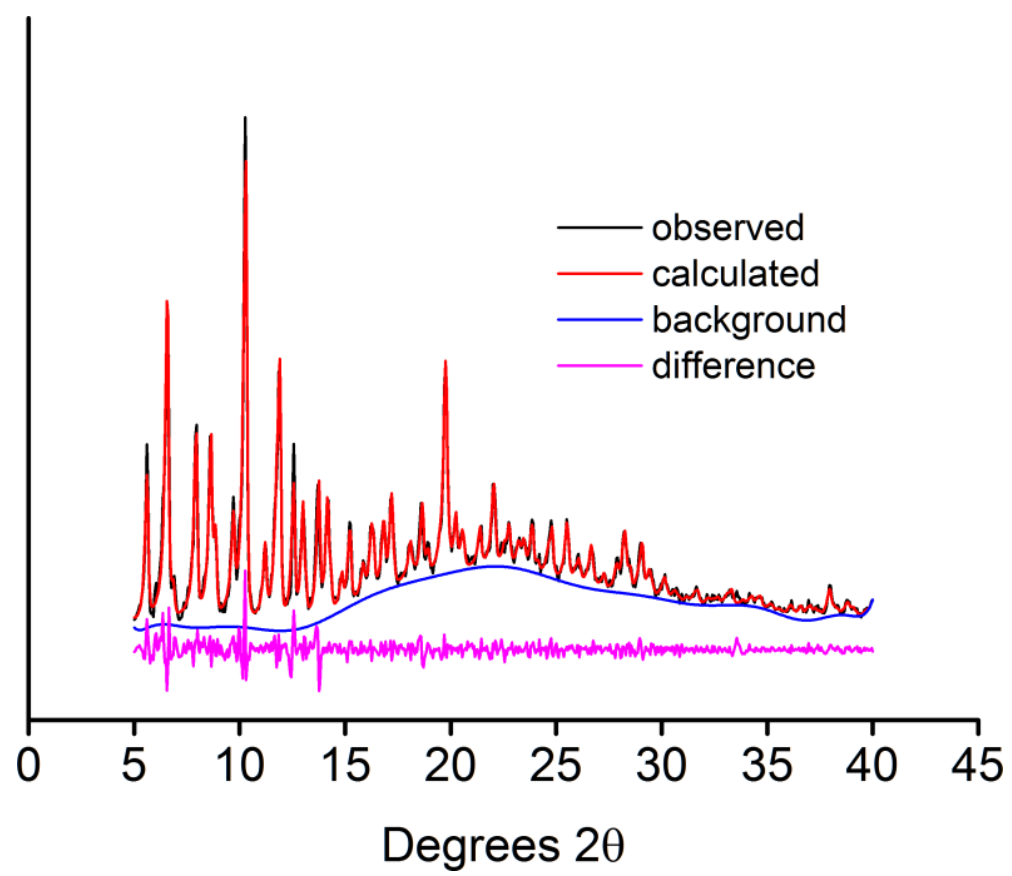

Figure S3. LeBail method fit to PXRD data for URMOF-2

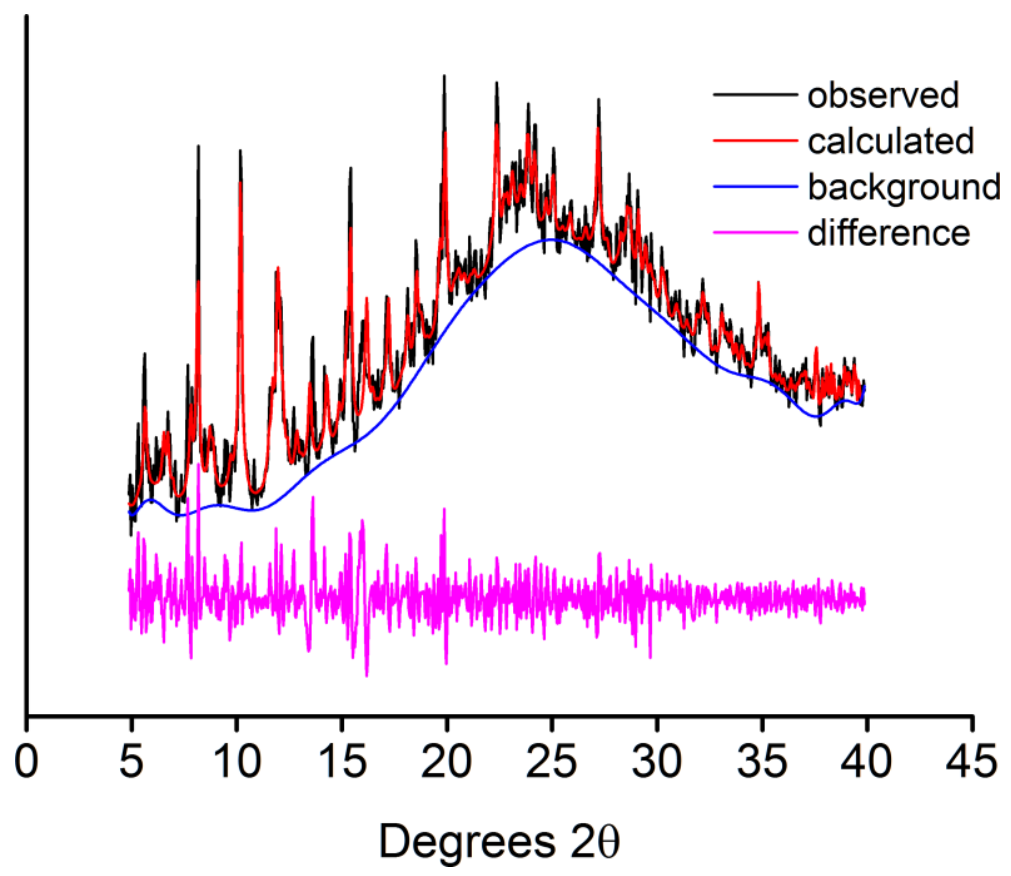

Figure S4. LeBail method fit to PXRD data for post-catalysis URMOF-2 


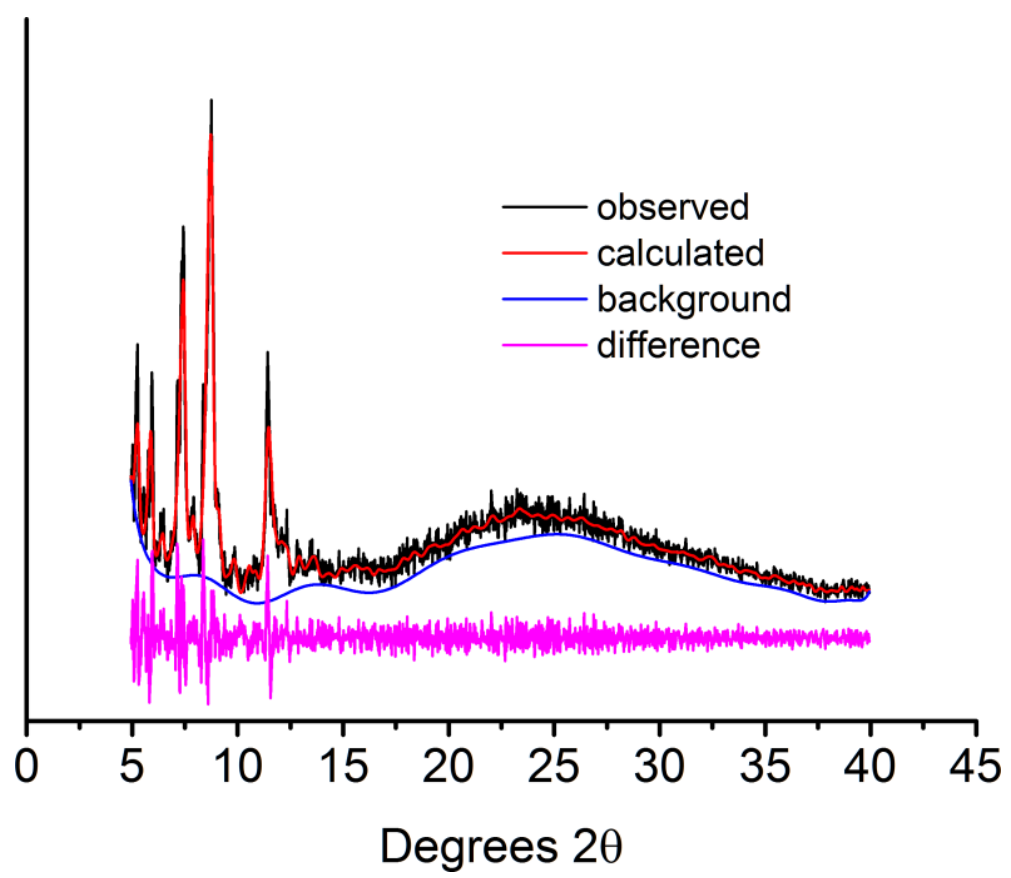

Figure S5. LeBail method fit to PXRD data for URMOF-3

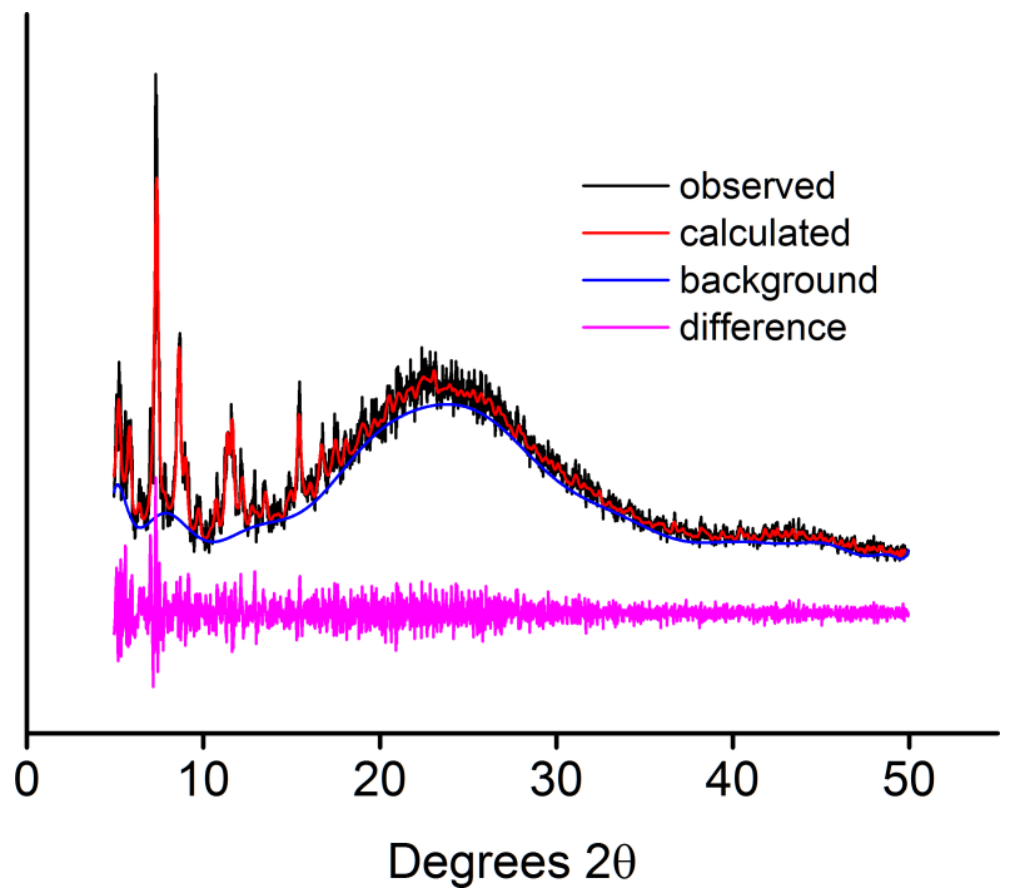

Figure S6. LeBail method fit to PXRD data for post-catalysis URMOF-3 


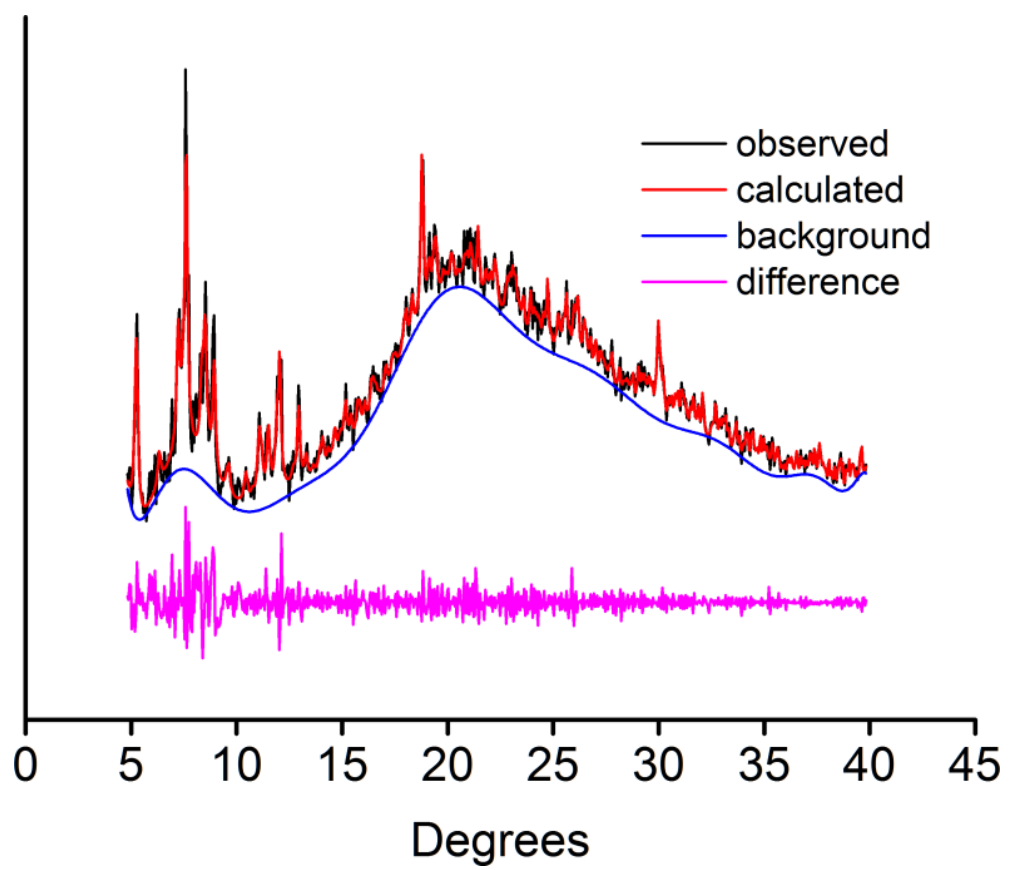

Figure S7. LeBail method fit to PXRD data for URMOF-4

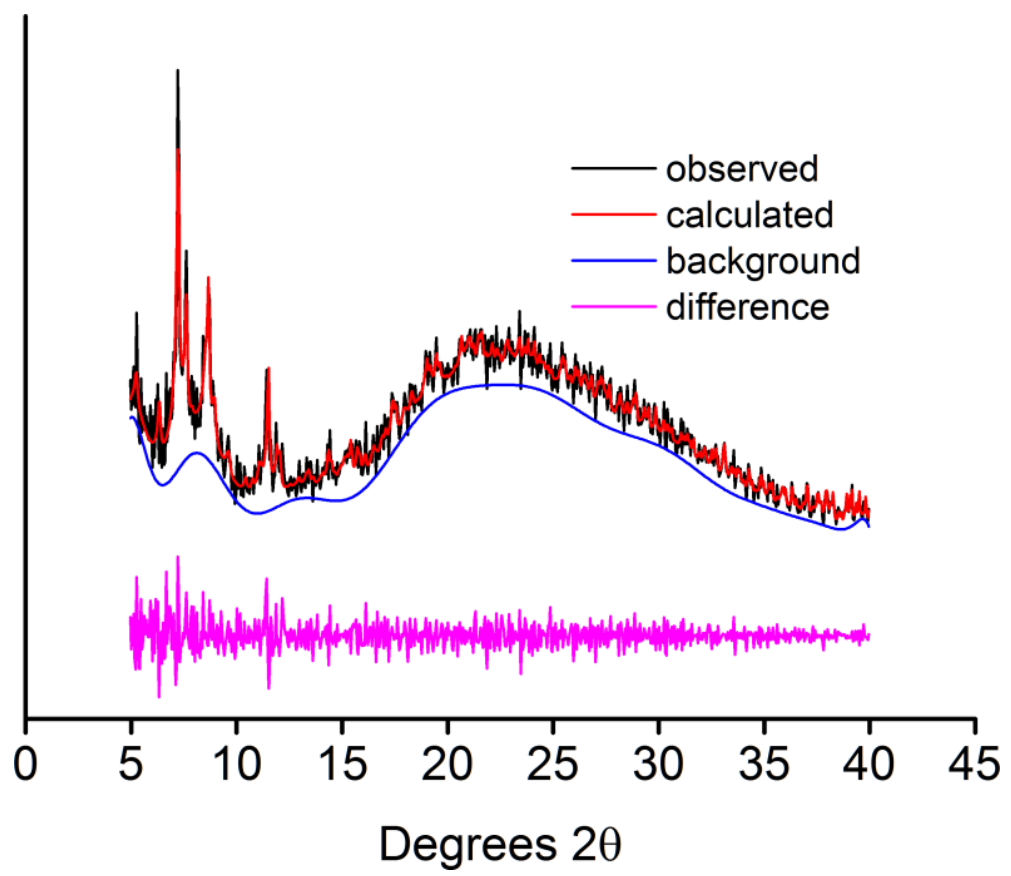

Figure S8. LeBail method fit to PXRD data for post-catalysis URMOF-4. 


\section{TGA of URMOF-1-4}

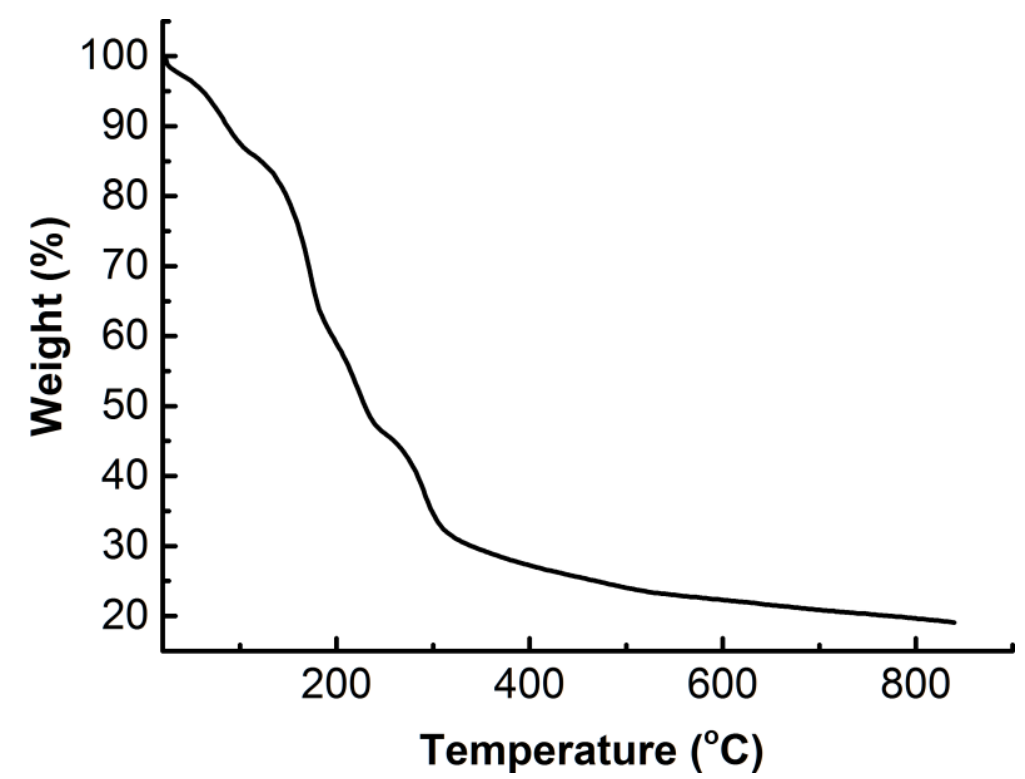

Figure S9. Thermogravimetric curves for URMOF-1.

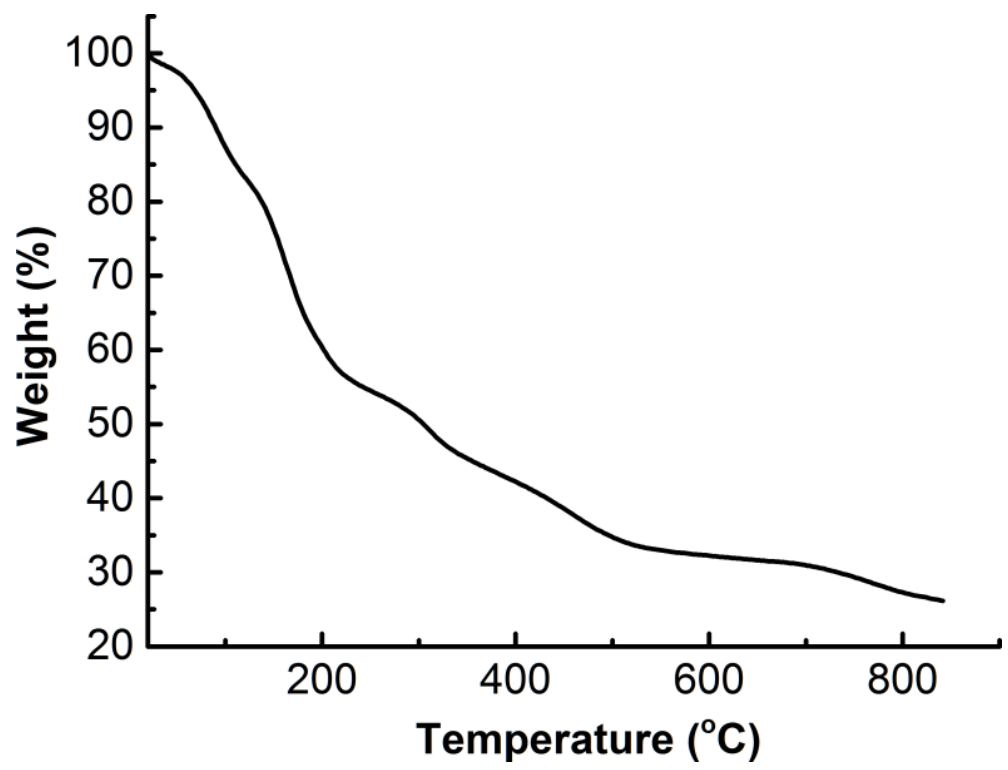

Figure S10. Thermogravimetric curves for URMOF-2. 


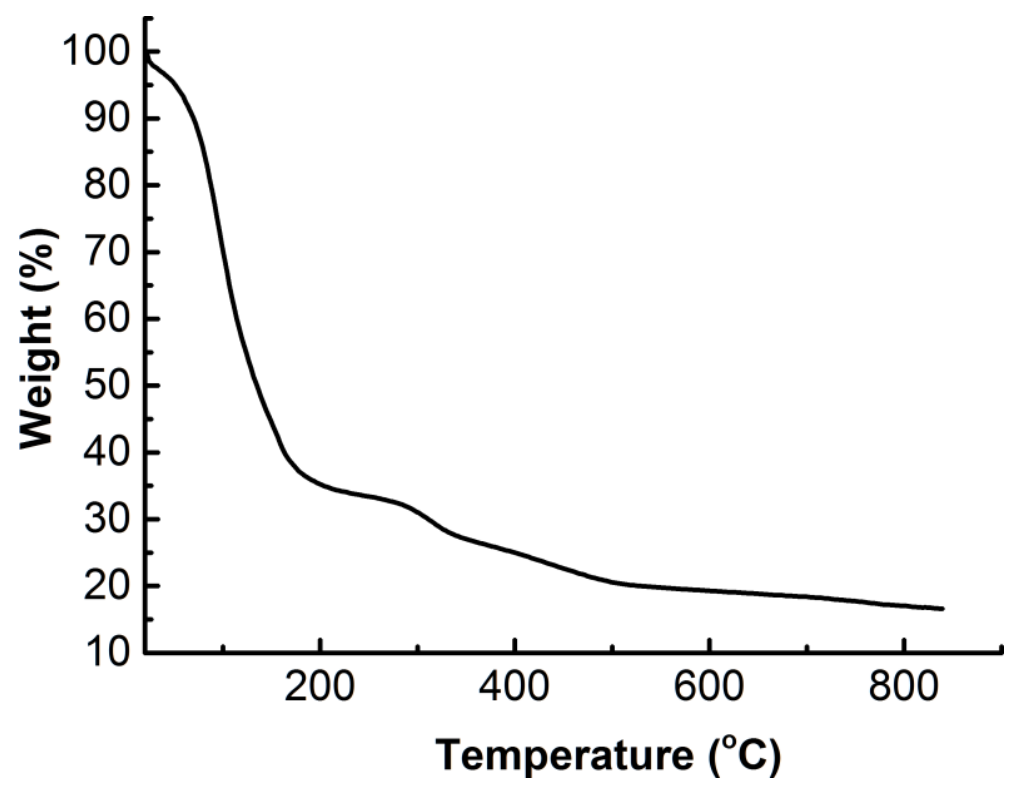

Figure S11. Thermogravimetric curves for URMOF-3.

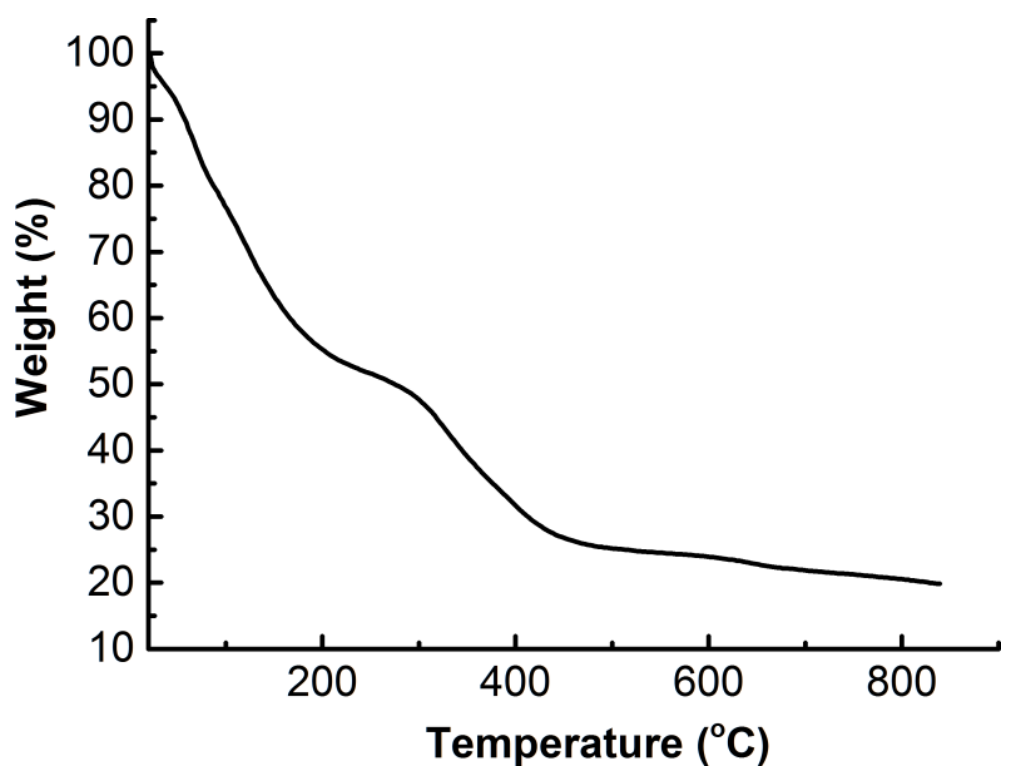

Figure S12. Thermogravimetric curves for URMOF-4. 


\section{The syntheses of nitroalkene substrates (S2-4)}

Different aldehyde $10 \mathrm{mmol}$ and nitromethane $10 \mathrm{mmol}$ were dissolved in $100 \mathrm{~mL} 95 \%$ ethanol, 12 mmol solid $\mathrm{NaOH}$ was added slowly at $0{ }^{\circ} \mathrm{C}$, the mixture was stirred violently for $12 \mathrm{~h}$, then poured into $50 \mathrm{~mL} 3 \mathrm{~N}$ hydrochloric acid and stirred for $15 \mathrm{~min}, 200 \mathrm{~mL}$ cool water was added subsequently, the solution was extracted with DCM $(50 \mathrm{~mL} \times 3)$, the combined organic layer were dried over anhydrous $\mathrm{NaSO}_{4}$ and concentrated in vacuum. The residue was purified by column chromatography using petroleum ether: DCM as eluent $(2 / 1, \mathrm{v} / \mathrm{v})$ to give tile compounds.

\section{Method b for $S_{3}$ and $S_{4}$}

Cinnamaldehyde $(10 \mathrm{mmol})$ or amylcinnaldehyde $(10 \mathrm{mmol})$ and nitromethane $(30 \mathrm{~mL})$ was introduced into a flask, a catalytic amount of ammonium acetate $(3 \mathrm{mmol})$ was added and then stirred at $100{ }^{\circ} \mathrm{C}$ for $5 \mathrm{~h}$. The reaction mixture was cooled and treated with ethyl acetate $(100 \mathrm{~mL})$ and water $(200 \mathrm{~mL})$ and then extracted by ethyl acetate $(50 \mathrm{~mL} \times 3)$. The combined extraction was washed by brine, dried over anhydrous $\mathrm{NaSO}_{4}$ and concentrated in vacuum. The residue was purified by column chromatography using petroleum ether: DCM as eluent (2/1, v/v) to give $\mathbf{S}_{\mathbf{3}}$ or $\mathbf{S}_{\mathbf{4}}$

(E)-(2-nitrovinyl)benzene $\left(\mathbf{S}_{\mathbf{1}}\right)$ was purchased from commercial sources and used without further $\curvearrowright \mathrm{NO}_{2}$ purification.

(E)-1-bromo-3-(2-nitrovinyl)benzene $\left(\mathbf{S}_{2}\right)$<smiles>O=[N+]([O-])C=Cc1cccc(Br)c1</smiles>

${ }^{1} \mathrm{H}$ NMR (400MHz, $\left.\mathrm{CDCl}_{3}\right): \delta$ 7.90-7.99 (d, 1H), $7.72(\mathrm{~s}, 1 \mathrm{H}), 7.61-7.68(\mathrm{~d}, 1 \mathrm{H})$, 7.54-7.61 (d, 1H), 7.46-7.54 (d, 1H), 7.32-7.40 (t, 1H). ${ }^{13} \mathrm{C}$ NMR $(100 \mathrm{MHz}$, $\left.\mathrm{CDCl}_{3}\right): \delta 138.1,137.4,134.9,132.1,131.7,130.9,127.7,123.4$. ESI-MS: $\mathrm{m} / \mathrm{z}$ $[\mathrm{M}+\mathrm{H}]^{+} 229$.

((1E,3E)-4-nitrobuta-1,3-dien-1-yl)benzene $\left(S_{3}\right)$

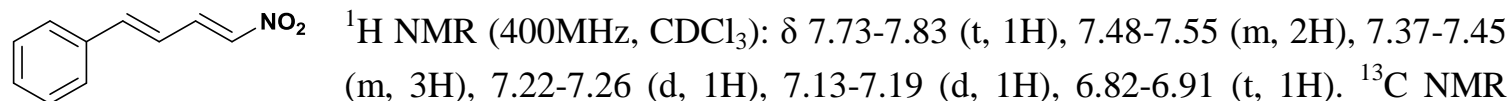
$(\mathrm{m}, 3 \mathrm{H}), 7.22-7.26(\mathrm{~d}, 1 \mathrm{H}), 7.13-7.19(\mathrm{~d}, 1 \mathrm{H}), 6.82-6.91(\mathrm{t}, 1 \mathrm{H}) .{ }^{13} \mathrm{C} \mathrm{NMR}$ $\left(100 \mathrm{MHz}, \mathrm{CDCl}_{3}\right): \delta 146.2,139.3,138.7,135.3,130.5,129.2,127.9,120.7$.

ESI-MS: m/z [M+H] $]^{+} 176$.

\section{((E)-2-((E)-2-nitrovinyl)hept-1-en-1-yl)benzene $\left(\mathbf{S}_{\mathbf{4}}\right)$}

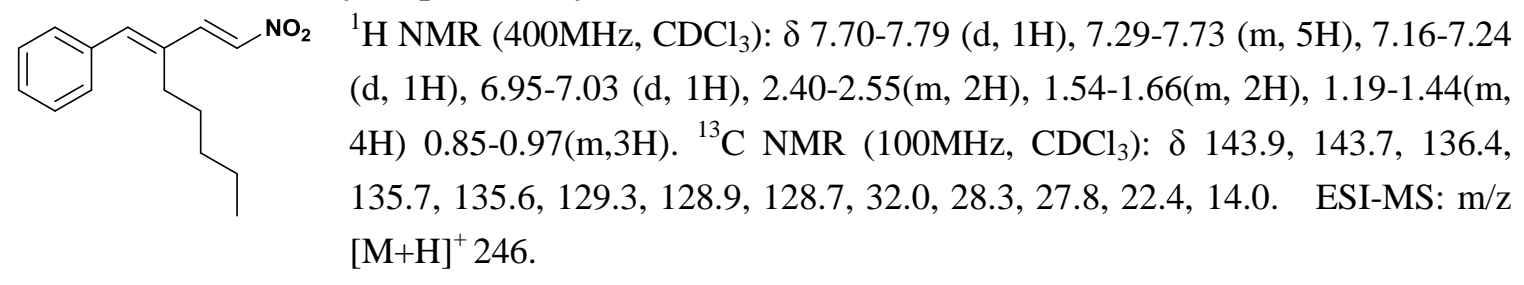




\section{The syntheses of the reported MOFs}

$\mathrm{Cu}_{3}$ (BTC) $)_{2}{ }^{\mathrm{S} 3}$ A solution of $\mathrm{Cu}\left(\mathrm{NO}_{3}\right)_{2} \cdot 2.5 \mathrm{H}_{2} \mathrm{O}(0.124 \mathrm{~g}, 0.532 \mathrm{mmol})$ and $\mathrm{H}_{3} \mathrm{BTC}(0.074 \mathrm{~g}, 0.352$ $\mathrm{mmol})$ in the mixture of $\mathrm{N}, \mathrm{N}$-dimethylformamide (DMF) $(6 \mathrm{ml}) /$ ethanol $(6 \mathrm{ml}) / \mathrm{H}_{2} \mathrm{O}(6 \mathrm{~mL})$ in a sealed vial $(20 \mathrm{~mL})$ was heated at $70{ }^{\circ} \mathrm{C}$ for $24 \mathrm{~h}$ gave green, cubic microcrystalline of $\mathrm{Cu}_{3}(\mathrm{BTC})_{2}$. The product was confirmed by a powder X-ray diffraction study.

MOF-14: ${ }^{\mathrm{S} 4} \quad 4,4^{\prime}, 4^{\prime \prime}$-benzene-1,3,5-triyl-tri-benzoic acid $\left(\mathrm{H}_{3} \mathrm{BTB} ; 0.023 \mathrm{~g}, 0.052 \mathrm{mmol}\right)$ and $\mathrm{Cu}\left(\mathrm{NO}_{3}\right)_{2} \cdot 2.5 \mathrm{H}_{2} \mathrm{O}(0.065 \mathrm{~g}, 0.28 \mathrm{mmol})$ were dissolved in a solvent mixture of ethanol ( $\left.3 \mathrm{~mL}\right)$, DMF $(3 \mathrm{~mL})$ and water $(2 \mathrm{ml})$ in the presence of excess pyridine $(0.62 \mathrm{mmol})$. The solution was heated at $65{ }^{\circ} \mathrm{C}$ for 1 day produced green cubic crystal in high yield. The product was confirmed by a powder X-ray diffraction study.

MOF-177: ${ }^{\mathrm{S} 5}$ A solution of $5 \mathrm{~mL}$ N,N-diethylformamide (DEF) containing 4,4',4"-benzene-1,3,5 -triyl-tri-benzoic acid $\left(\mathrm{H}_{3} \mathrm{BTB} ; 5 \mathrm{mg}\right)$ and $\mathrm{Zn}\left(\mathrm{NO}_{3}\right)_{2} \cdot 6 \mathrm{H}_{2} \mathrm{O}(20 \mathrm{mg})$ in a sealed vial was heated at $100{ }^{\circ} \mathrm{C}$ for $23 \mathrm{~h}$, and then cooled to room temperature. Block-shaped crystals of MOF-177 were formed and washed by DEF. The product was confirmed by a powder X-ray diffraction study.

$\mathbf{I n}_{3} \mathbf{O}-\mathbf{M O F}:{ }^{\mathrm{S} 6} 1,3-\mathrm{H}_{2} \mathrm{BDC}(30 \mathrm{mg}, 0.174 \mathrm{mmol}), \mathrm{In}\left(\mathrm{NO}_{3}\right)_{3} \cdot 2 \mathrm{H}_{2} \mathrm{O}(30 \mathrm{mg}, 0.087 \mathrm{mmol}), \mathrm{DMF}(1 \mathrm{~mL})$, $\mathrm{CH}_{3} \mathrm{CN}(1 \mathrm{~mL})$, imidazole $(0.2 \mathrm{~g})$, and $\mathrm{HNO}_{3}(0.2 \mathrm{~mL})$ were added to a sealed vial, and the solution was heated to $85{ }^{\circ} \mathrm{C}$ for $12 \mathrm{~h}$ and then at $100{ }^{\circ} \mathrm{C}$ for $20 \mathrm{~h}$. Colorless cubic crystals were collected and air-dried. The product was confirmed by a powder X-ray diffraction study. 


\section{PXRD patterns for the reported MOFs}

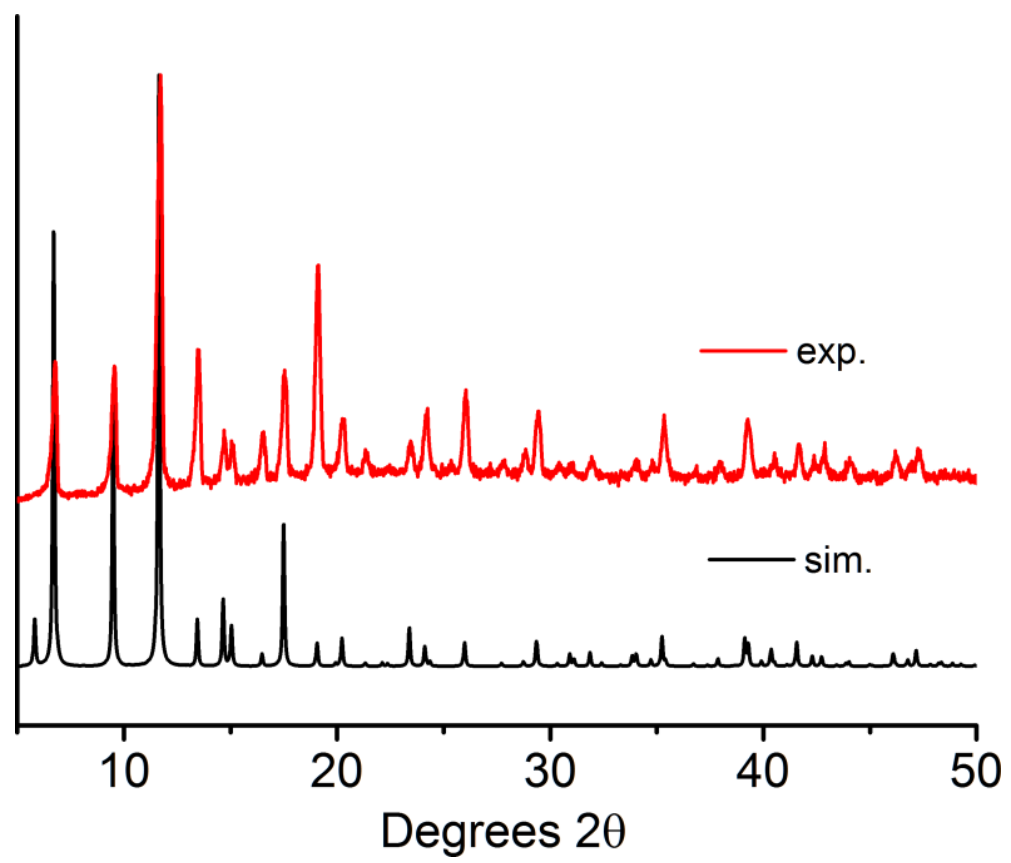

Figure $\mathrm{S} 13$ experimental and simulated PXRD patterns of $\mathrm{Cu}_{3}(\mathrm{BTC})_{2}$

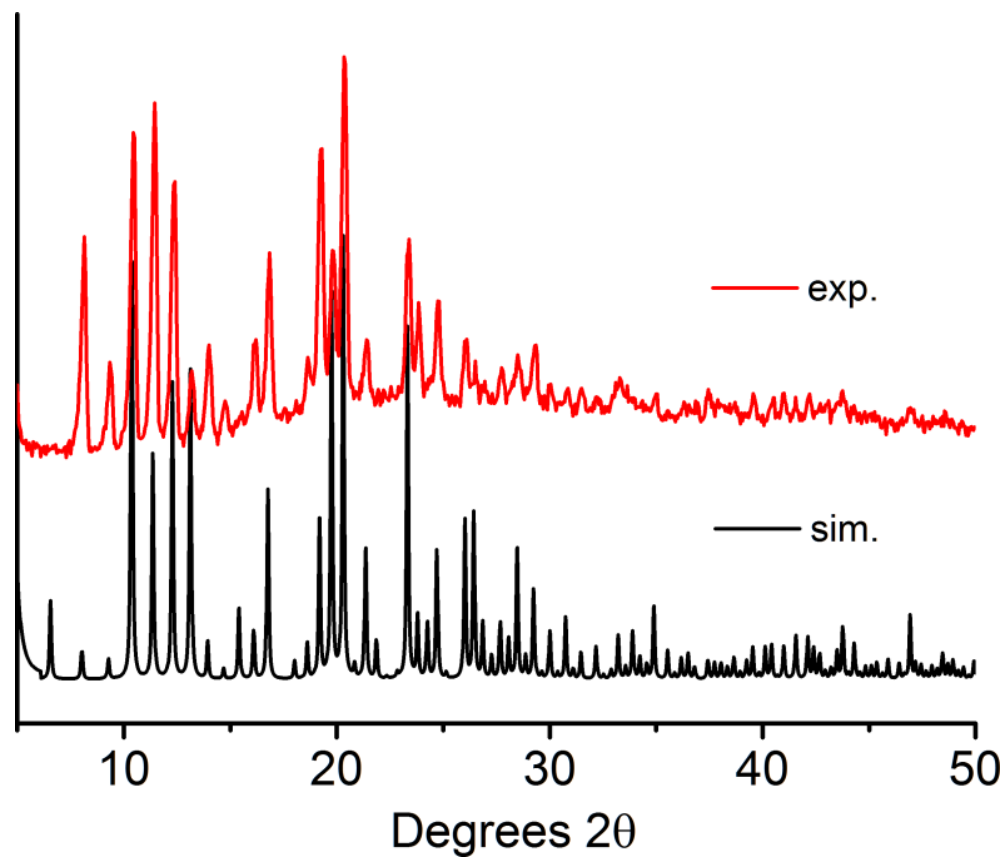

Figure S14 experimental and simulated PXRD patterns of MOF-14 


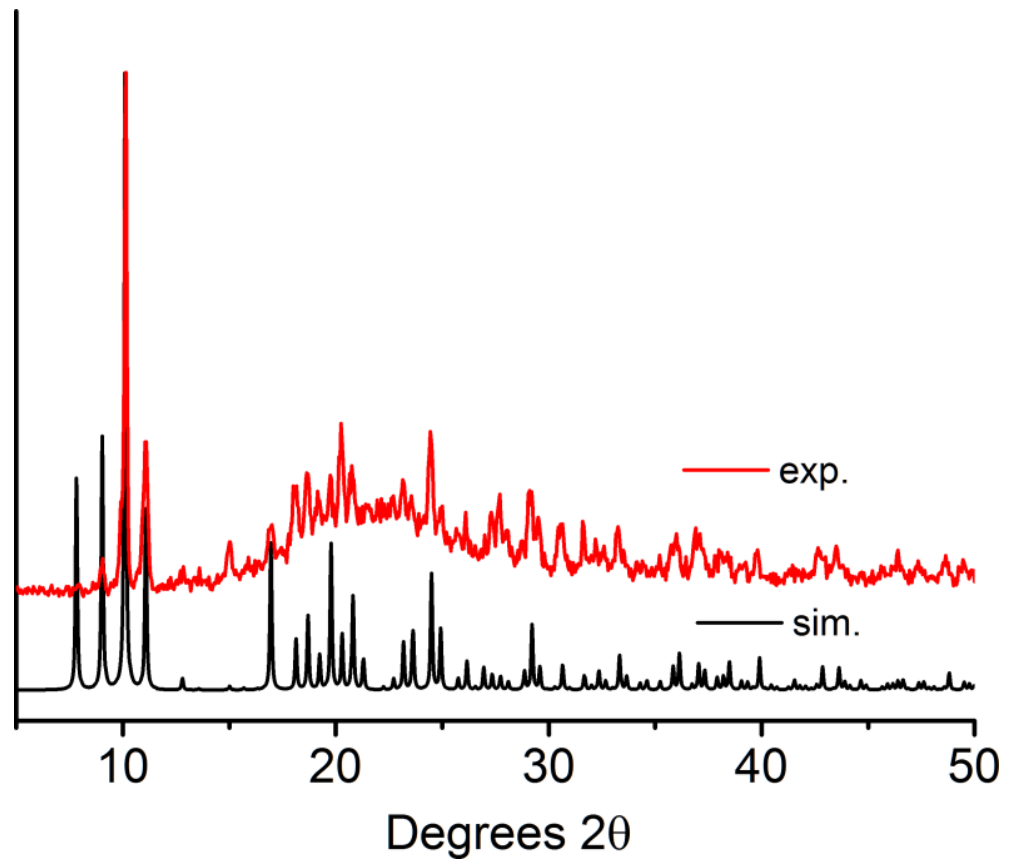

Figure S15 experimental and simulated PXRD patterns of $\mathrm{In}_{3} \mathrm{O}-\mathrm{MOF}$

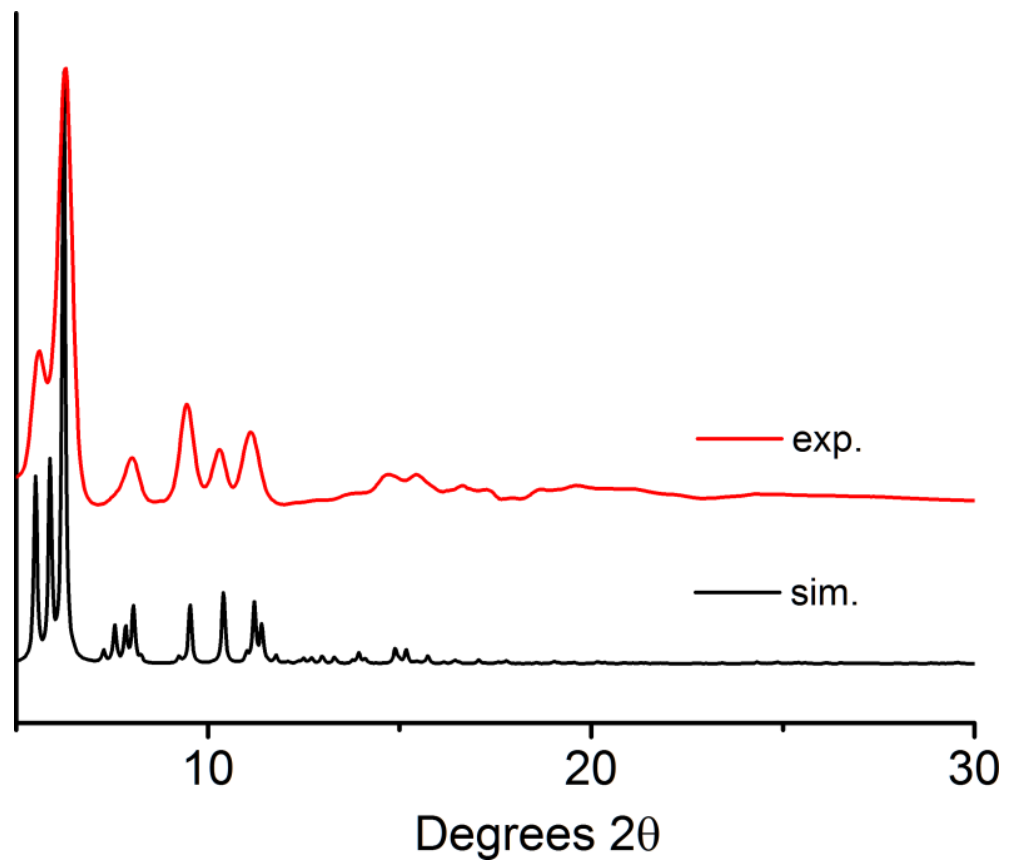

Figure S16 experimental and simulated PXRD patterns of MOF-177 


\section{Typical experimental procedure for catalysis}

To a solution of nitroalkene substrates $(0.5 \mathrm{mmol})$ and nucleophiles $(1.5 \mathrm{mmol})$ in $0.75 \mathrm{~mL} \mathrm{CH}_{3} \mathrm{CN}$, MOFs $\left(0.05 \mathrm{mmol}\right.$, based on per urea unit) was added. The reaction mixture was heated at $60{ }^{\circ} \mathrm{C}$ and stirred for 24-48 $\mathrm{h}$ and then cooled and filtered. The filtration was concentrated in vacuum and then purified by silica-gel column chromatography using petroleum ether: DCM as eluent $(2 / 1, \mathrm{v} / \mathrm{v})$ to obtain the products.

\section{1-Methyl-2-(2-nitro-1-phenylethyl)-1H-pyrrole}

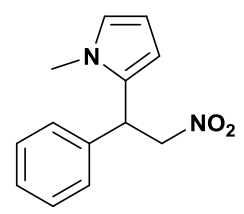

${ }^{1} \mathrm{H}$ NMR (400 MHz, $\left.\mathrm{CDCl}_{3}\right): \delta 7.36-7.20(\mathrm{~m}, 3 \mathrm{H}), 7.20-7.10(\mathrm{~m}, 2 \mathrm{H}), 6.62-6.54$ (m, 1H), 6.18-6.06 (m, 2H), 4.91-5.00 (m, 1H), 4.90-4.82 (m, 1H), 4.69-4.79 (m, $1 \mathrm{H}), 3.35$ (s, 3H). ${ }^{13} \mathrm{C} \mathrm{NMR}\left(100 \mathrm{MHz}, \mathrm{CDCl}_{3}\right): \delta 138.2,129.4,129.2,128.0,128.0$, 123.1, 107.0, 106.0, 79.6, 41.9, 33.8. ESI-MS: $\mathrm{m} / \mathrm{z}[\mathrm{M}+\mathrm{H}]^{+} 231$.

\section{2-(1-(3-bromophenyl)-2-nitroethyl)-1-methyl-1H-pyrrole}<smiles>Cn1cccc1C(C[N+](=O)[O-])c1cccc(Br)c1</smiles>

${ }^{1} \mathrm{H}$ NMR $\left(400 \mathrm{MHz}, \mathrm{CDCl}_{3}\right): \delta 7.45-7.33(\mathrm{~m}, 2 \mathrm{H}), 7.25-7.10(\mathrm{~m}, 2 \mathrm{H}), 6.66-$ $6.60(\mathrm{~s}, 1 \mathrm{H}), 6.20-6.11(\mathrm{~d}, 2 \mathrm{H}), 4.61-5.07(\mathrm{~m}, 3 \mathrm{H}), 3.26-3.48(\mathrm{~d}, 3 \mathrm{H}) .{ }^{13} \mathrm{C}$ $\operatorname{NMR}\left(100 \mathrm{MHz}, \mathrm{CDCl}_{3}\right): \delta 140.6,131.2,131.0,130.7,128.5,126.7,123.3$, 123.2, 107.2, 106.3, 79.2, 41.3, 33.9. ESI-MS: $\mathrm{m} / \mathrm{z}[\mathrm{M}+\mathrm{H}]^{+} 310$.

\section{(E)-1-methyl-2-(1-nitro-4-phenylbut-3-en-2-yl)-1H-pyrrole}

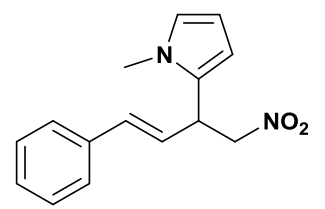

${ }^{1} \mathrm{H}$ NMR $\left(400 \mathrm{MHz}, \mathrm{CDCl}_{3}\right): \delta 7.41-7.26(\mathrm{~m}, 5 \mathrm{H}), 6.66-6.60(\mathrm{~m}, 1 \mathrm{H}), 6.50$ $6.40(\mathrm{~m}, 1 \mathrm{H}), 6.20-6.09(\mathrm{~m}, 1 \mathrm{H}), 6.06-5.97(\mathrm{~m}, 1 \mathrm{H}), 4.82-4.73(\mathrm{~m}, 1 \mathrm{H}), 4.90$ $4.82(\mathrm{~m}, 1 \mathrm{H}), 4.50-4.37(\mathrm{~m}, 1 \mathrm{H}), 3.62(\mathrm{~s}, 3 \mathrm{H}) .{ }^{13} \mathrm{C} \mathrm{NMR}\left(100 \mathrm{MHz}, \mathrm{CDCl}_{3}\right): \delta$ 136.1, 133.4, 128.6, 128.1, 126.6, 126.3, 123.0, 107.3, 105.7, 78.4, 39.3, 33.9.

ESI-MS: $\mathrm{m} / \mathrm{z}[\mathrm{M}+\mathrm{H}]^{+} 257$.

\section{(E)-2-(3-benzylidene-1-nitrooctan-2-yl)-1-methyl-1H-pyrrole}

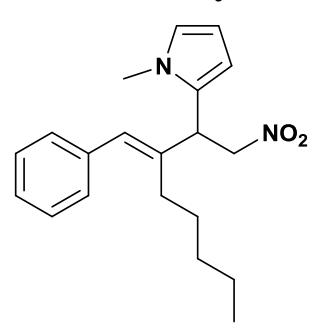

${ }^{1} \mathrm{H}$ NMR (400 MHz, $\mathrm{CDCl}_{3}$ ): $\delta$ 7.43-7.27 (m, 2H), 7.26-7.07 (m, 3H), $6.62(\mathrm{~s}$, $1 \mathrm{H}), 6.38(\mathrm{~s}, 1 \mathrm{H}), 6.17-5.964(\mathrm{t}, 2 \mathrm{H}), 4.85-4.75(\mathrm{t}, 2 \mathrm{H}), 4.49-4.35(\mathrm{~d}, 1 \mathrm{H}), 3.63-$ $3.55(\mathrm{t}, 3 \mathrm{H}), 2.25-2.09(\mathrm{~m}, 2 \mathrm{H}), 1.12-1.33(\mathrm{~m}, 6 \mathrm{H}), 0.87-0.73(\mathrm{~s}, 3 \mathrm{H}) .{ }^{13} \mathrm{C}$ NMR $\left(100 \mathrm{MHz}, \mathrm{CDCl}_{3}\right): \delta 139.3,137.1,129.7,128.5,128.4,128.3,126.9,123.0$, $107.1,106.8,77.5,43.8,33.9,32.0,29.5,28.2,22.1,13.9$. ESI-MS: $\mathrm{m} / \mathrm{z}$ $[\mathrm{M}+\mathrm{H}]^{+} 327$.

\section{1-methyl-3-(2-nitro-1-phenylethyl)-1H-indole}

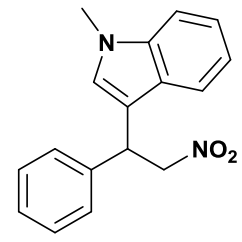

${ }^{1} \mathrm{H}$ NMR $\left(400 \mathrm{MHz}, \mathrm{CDCl}_{3}\right): \delta 7.45(\mathrm{~m}, 1 \mathrm{H}), 7.38-7.18(\mathrm{~m}, 7 \mathrm{H}), 7.13-7.01(\mathrm{~m}$, $1 \mathrm{H}), 6.91-6.81(\mathrm{~m}, 1 \mathrm{H}), 5.24-5.10(\mathrm{~m}, 1 \mathrm{H}), 5.10-4.99(\mathrm{~m}, 1 \mathrm{H}), 4.99-4.86(\mathrm{~m}, 1 \mathrm{H})$, $3.73(\mathrm{~s}, 3 \mathrm{H}) .{ }^{13} \mathrm{C}$ NMR $\left(100 \mathrm{MHz}, \mathrm{CDCl}_{3}\right): \delta 139.4,137.3,128.9,127.8,127.5$, 126.6, 126.4, 122.2, 119.4, 119.0, 112.8, 109.5, 79.5, 41.5, 32.8. ESI-MS: m/z $[\mathrm{M}+\mathrm{H}]^{+} 281$. 
3-(1-(3-bromophenyl)-2-nitroethyl)-1-methyl-1H-indole<smiles>Cn1cc(C(C[N+](=O)[O-])c2cccc(Br)c2)c2ccccc21</smiles>

${ }^{1} \mathrm{H}$ NMR $\left(400 \mathrm{MHz}, \mathrm{CDCl}_{3}\right): \delta$ 7.53-7.35 (m, 3H), 7.33-7.18 (m, 4H),7.13$7.03(\mathrm{~m}, 1 \mathrm{H}), 6.92-6.80(\mathrm{~m}, 1 \mathrm{H}), 5.21-5.09(\mathrm{~m}, 1 \mathrm{H}), 5.07-4.96(\mathrm{~m}, 1 \mathrm{H}), 4.95-$ $4.83(\mathrm{~m}, 1 \mathrm{H}), 3.76(\mathrm{~s}, 3 \mathrm{H}) .{ }^{13} \mathrm{C}$ NMR $\left(100 \mathrm{MHz}, \mathrm{CDCl}_{3}\right): \delta 141.8,137.3,130.9$, $130.8,130.5,126.4,126.4,126.3,123.0,122.4,119.7,118.8,112.1,109.5,79.2$, 41.1, 32.9. ESI-MS: $\mathrm{m} / \mathrm{z}[\mathrm{M}+\mathrm{H}]^{+} 360$.

(E)-1-methyl-3-(1-nitro-4-phenylbut-3-en-2-yl)-1H-indole<smiles>Cn1cc(/C=C/c2ccccc2)c2ccccc21</smiles>

${ }^{1} \mathrm{H}$ NMR $\left(400 \mathrm{MHz}, \mathrm{CDCl}_{3}\right): \delta$ 7.83-7.72 $(\mathrm{d}, 1 \mathrm{H}), 7.52-7.23(\mathrm{~m}, 8 \mathrm{H}), 7.02(\mathrm{~s}$, $1 \mathrm{H}), 6.77-6.64(\mathrm{~d}, 1 \mathrm{H}), 6.61-6.43(\mathrm{dd}, 1 \mathrm{H}), 4.96-4.72(\mathrm{~m}, 3 \mathrm{H}), 3.78(\mathrm{~s}, 3 \mathrm{H})$. ${ }^{13} \mathrm{C}$ NMR $\left(100 \mathrm{MHz}, \mathrm{CDCl}_{3}\right): \delta 137.4,136.7,132.5,128.7,127.9,127.4,126.6$, 126.6, 126.5, 122.3, 119.7, 119.1, 111.5, 109.9, 79.5, 39.6, 32.8. ESI-MS: m/z $[\mathrm{M}+\mathrm{H}]^{+} 307$

(E)-3-(3-benzylidene-1-nitrooctan-2-yl)-1-methyl-1H-indole

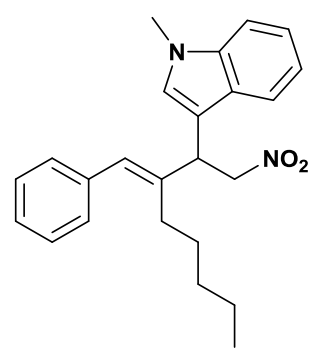

${ }^{1} \mathrm{H}$ NMR $\left(400 \mathrm{MHz}, \mathrm{CDCl}_{3}\right): \delta$ 7.73-7.61 $(\mathrm{m}, 1 \mathrm{H}), 7.43-7.19(\mathrm{~m}, 7 \mathrm{H}), 7.18-$ $7.08(\mathrm{~m}, 1 \mathrm{H}), 7.01-6.88(\mathrm{~m}, 1 \mathrm{H}), 6.62-6.50(\mathrm{~m}, 1 \mathrm{H}), 5.02-4.61(\mathrm{~m}, 3 \mathrm{H}), 3.78$ $(\mathrm{s}, 3 \mathrm{H}), 2.46-1.95(\mathrm{~m}, 2 \mathrm{H}), 1.53-1.40(\mathrm{~m}, 2 \mathrm{H}), 1.27-1.13(\mathrm{~m}, 4 \mathrm{H}), 0.87-0.69(\mathrm{~m}$, $3 \mathrm{H}),{ }^{13} \mathrm{C}$ NMR $\left(100 \mathrm{MHz}, \mathrm{CDCl}_{3}\right): \delta 141.2,137.5,137.4,128.7,128.2,127.2$, $126.9,126.6,126.1,122.1,119.5,118.9,111.5,109.6,78.3,41.4,32.9,31.9$, 30.9, 28.3, 22.3, 13.9. ESI-MS: m/z [M+H] 377 .

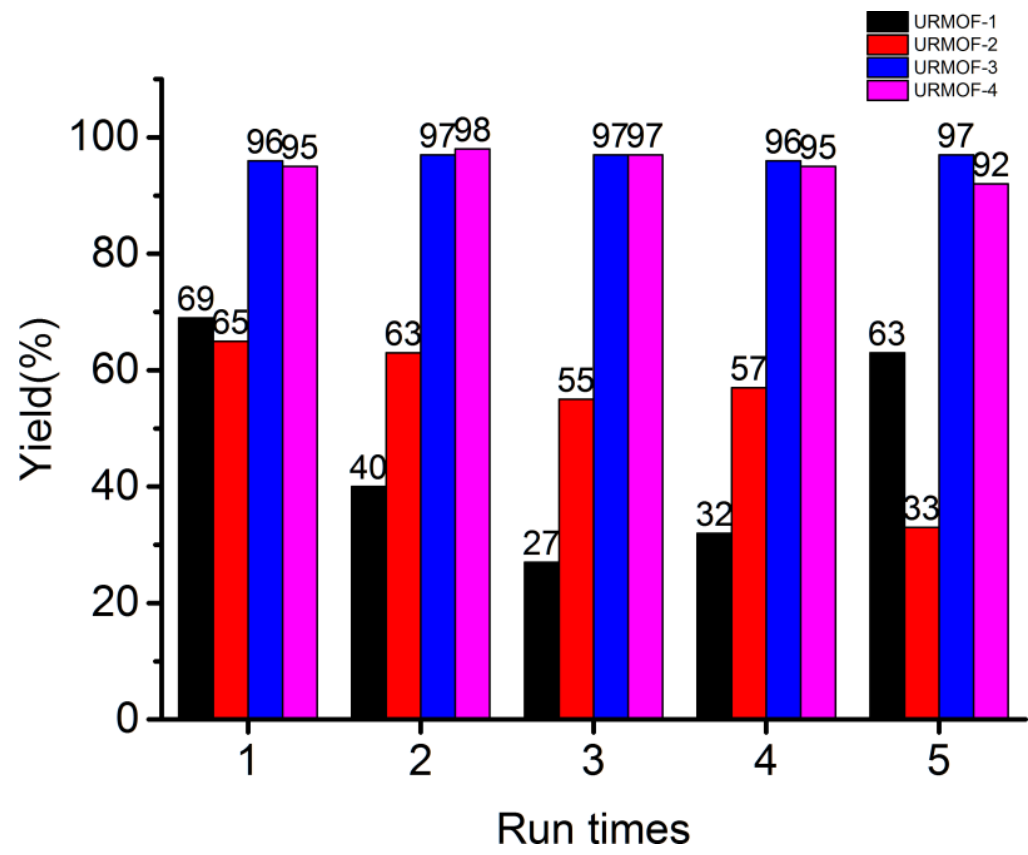

Figure S17. The recyclable results of URMOF-1-4 catalyzed Friedel-Craft alkylate for 1-methylindole. The reaction were carried out with 1-methylindole $(1.5 \mathrm{mmol}), \mathbf{S}_{\mathbf{1}}(0.5 \mathrm{mmol})$, URMOFs (10 mol\%), $\mathrm{CH}_{3} \mathrm{CN}(0.75 \mathrm{~mL})$ for $24 \mathrm{~h}$. 


\section{GCMC simulation}

The Grand canonical Monte Carlo (GCMC) simulations were performed using RASPA following the reported routine. ${ }^{\mathrm{S} 7} \mathrm{LJ}$ parameters for URMOF-1-4 atoms were taken from the DREIDING force field except for the copper atom; its parameters were taken from UFF. Partial charges for the atoms in MOF were derived from DFT calculations. Nitrogen molecules were modeled using the TraPPE force field. All GCMC simulations included a 10000 -cycle equilibration period followed by a 10000-cycle production run. A cycle consists of $\mathrm{n}$ Monte Carlo steps; where $\mathrm{n}$ is equal to the number of molecules (which fluctuates during a GCMC simulation). All simulations included random insertion/deletion, translation and rotation moves of molecules with equal probabilities. Atoms in MOF were held fixed at their

crystallographic positions. An LJ cutoff distance of $15.0 \AA$ was used for all simulations. The Ewald sum technique was used to compute the electrostatic interactions. Four unit cells of URMOF-1-4 were used for the simulations. $\mathrm{N}_{2}$ isotherms were simulated at $77.35 \mathrm{~K}$ up to 0.9 bar. BET surface areas and PSDs were obtained by using the data points on the simulated $\mathrm{N}_{2}$ adsorption isotherms.

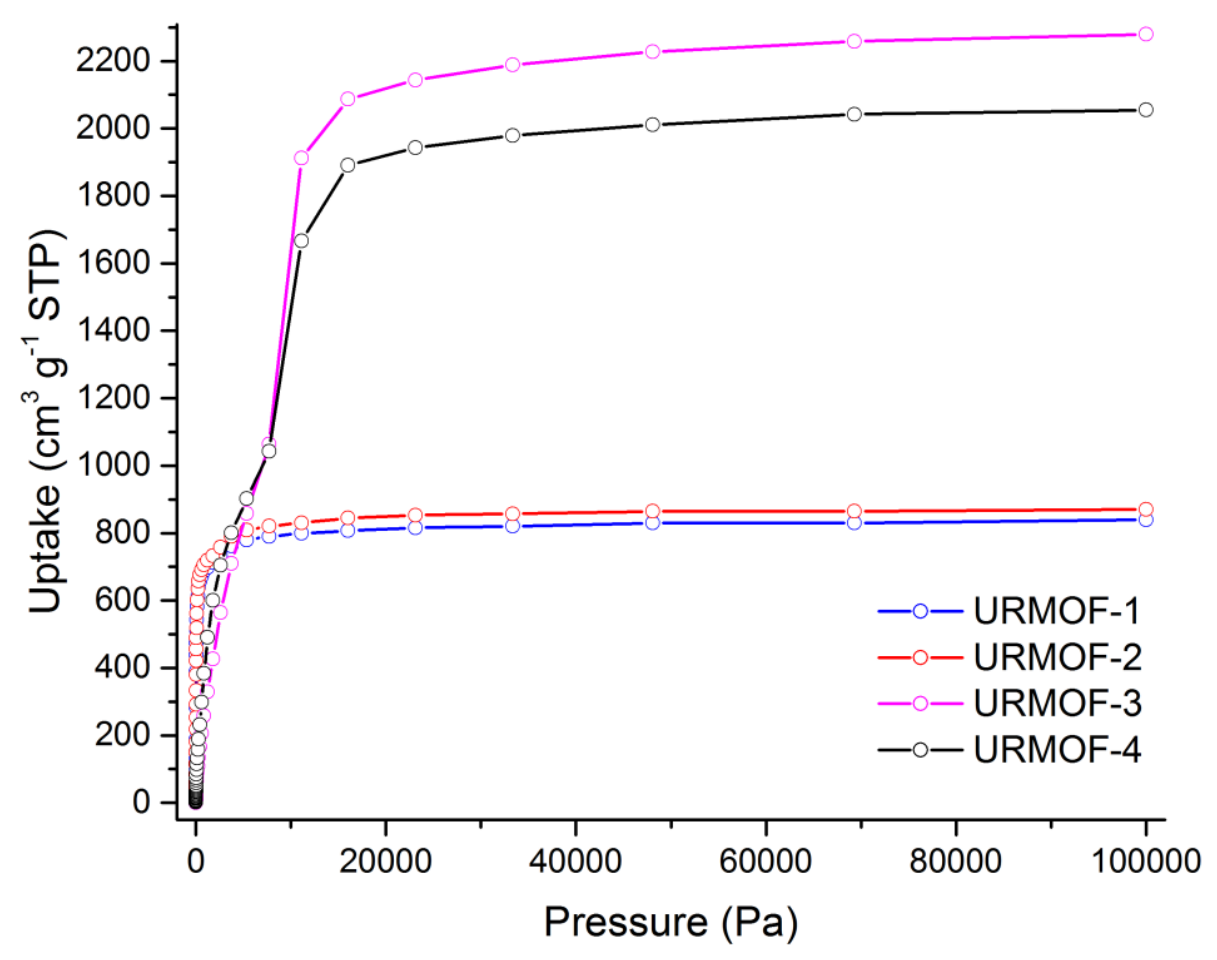

Figure S18. The GCMC $\mathrm{N}_{2}$ isotherms of URMOF-1-4 at $77.35 \mathrm{~K}$. 


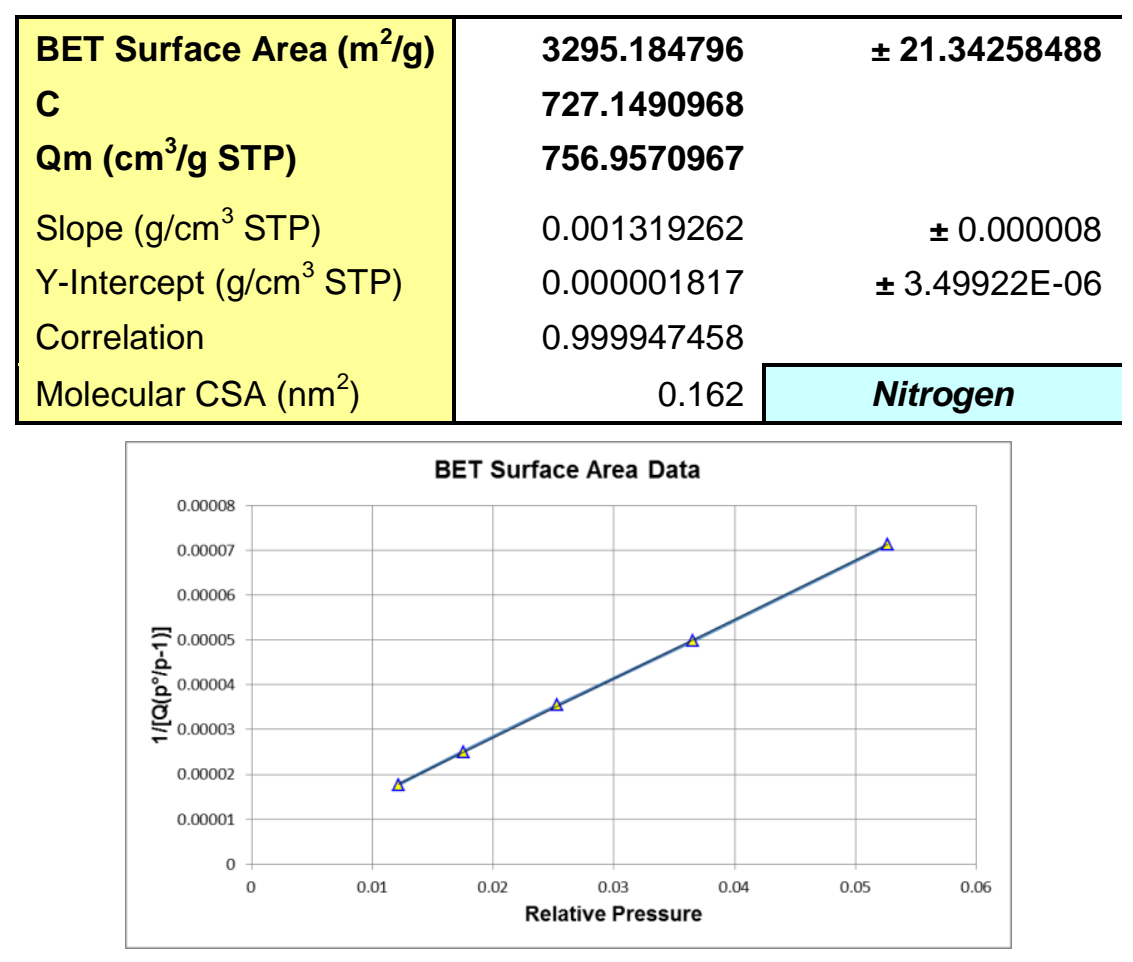

Figure S19. The fitting parameters and plot of the linear region for the BET equation for URMOF-1, which satisfies the first and second criterion for application of the BET theory.

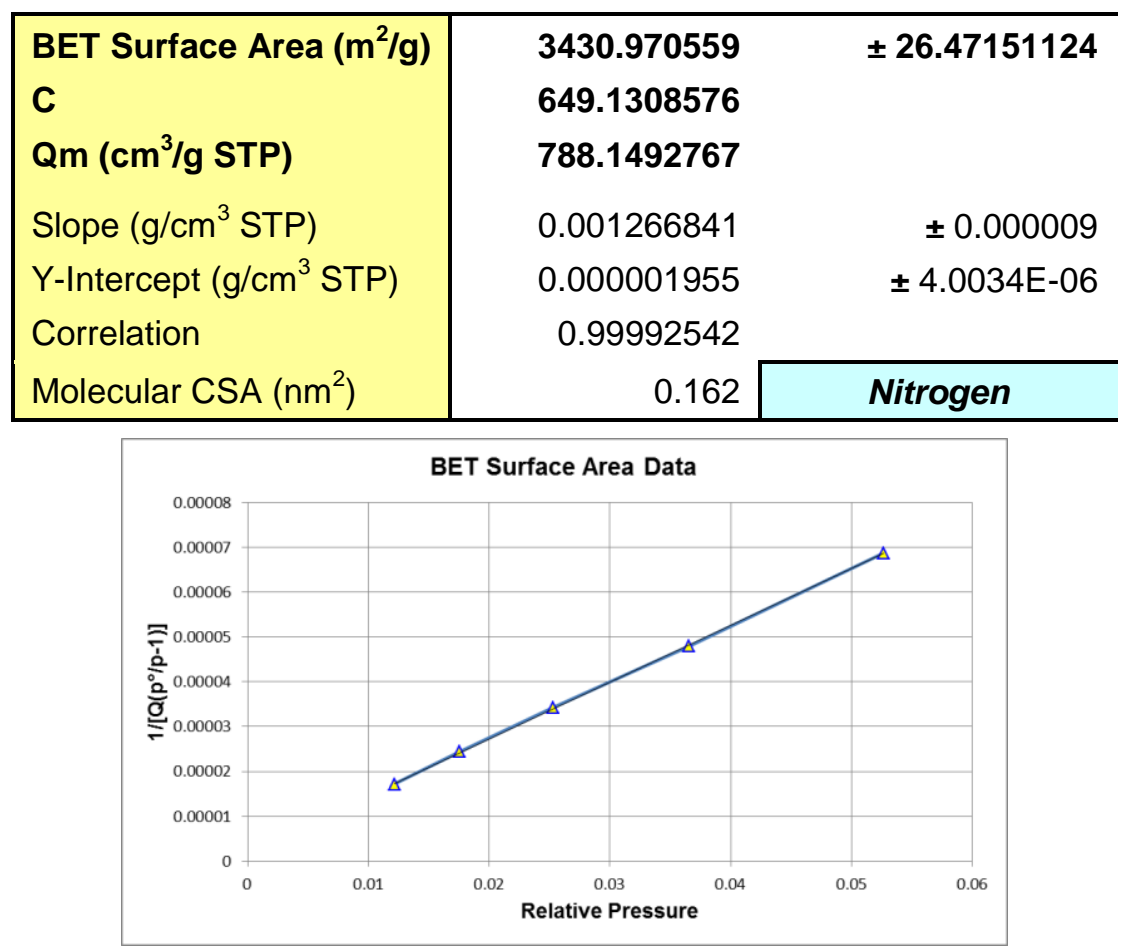

Figure S20. The fitting parameters and plot of the linear region for the BET equation for URMOF-2, which satisfies the first and second criterion for application of the BET theory. 


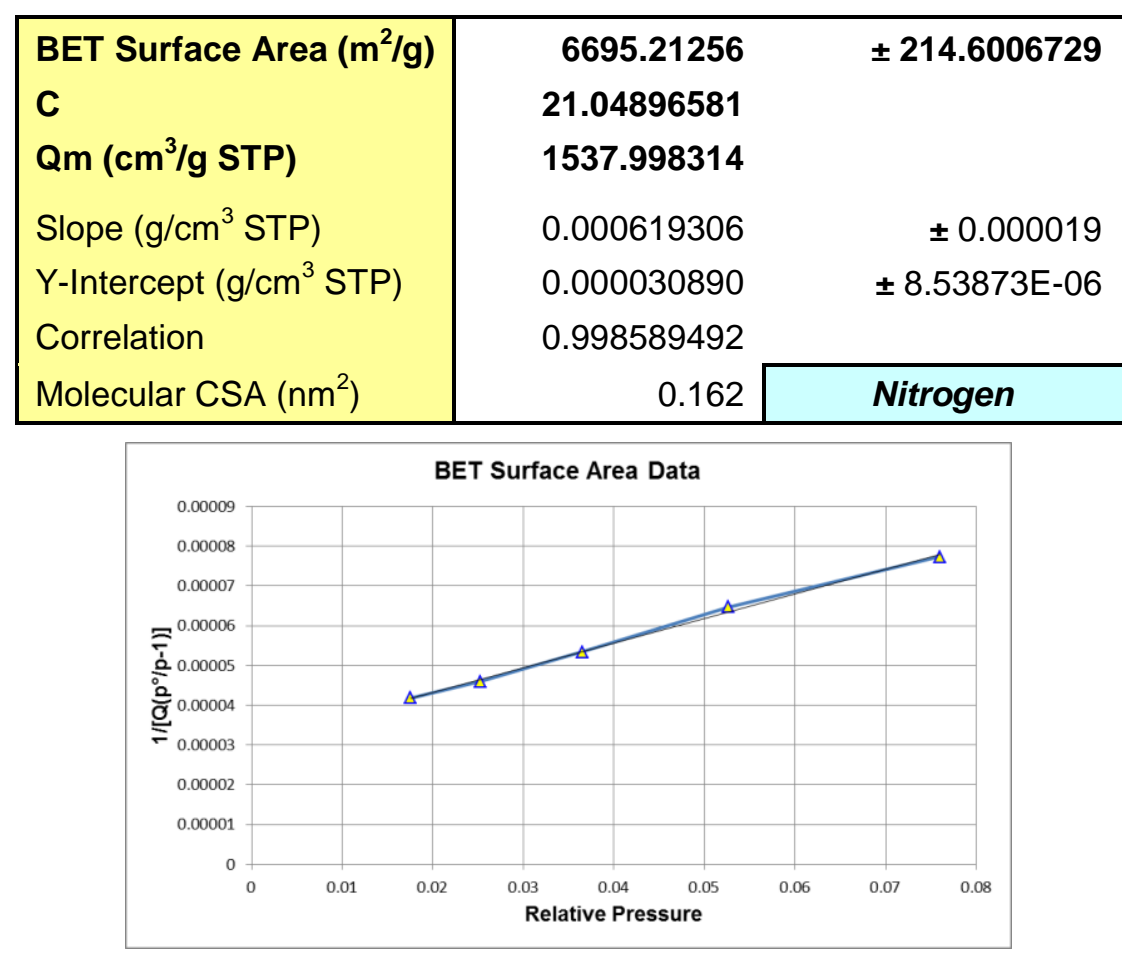

Figure S21. The fitting parameters and plot of the linear region for the BET equation for URMOF-3, which satisfies the first and second criterion for application of the BET theory.

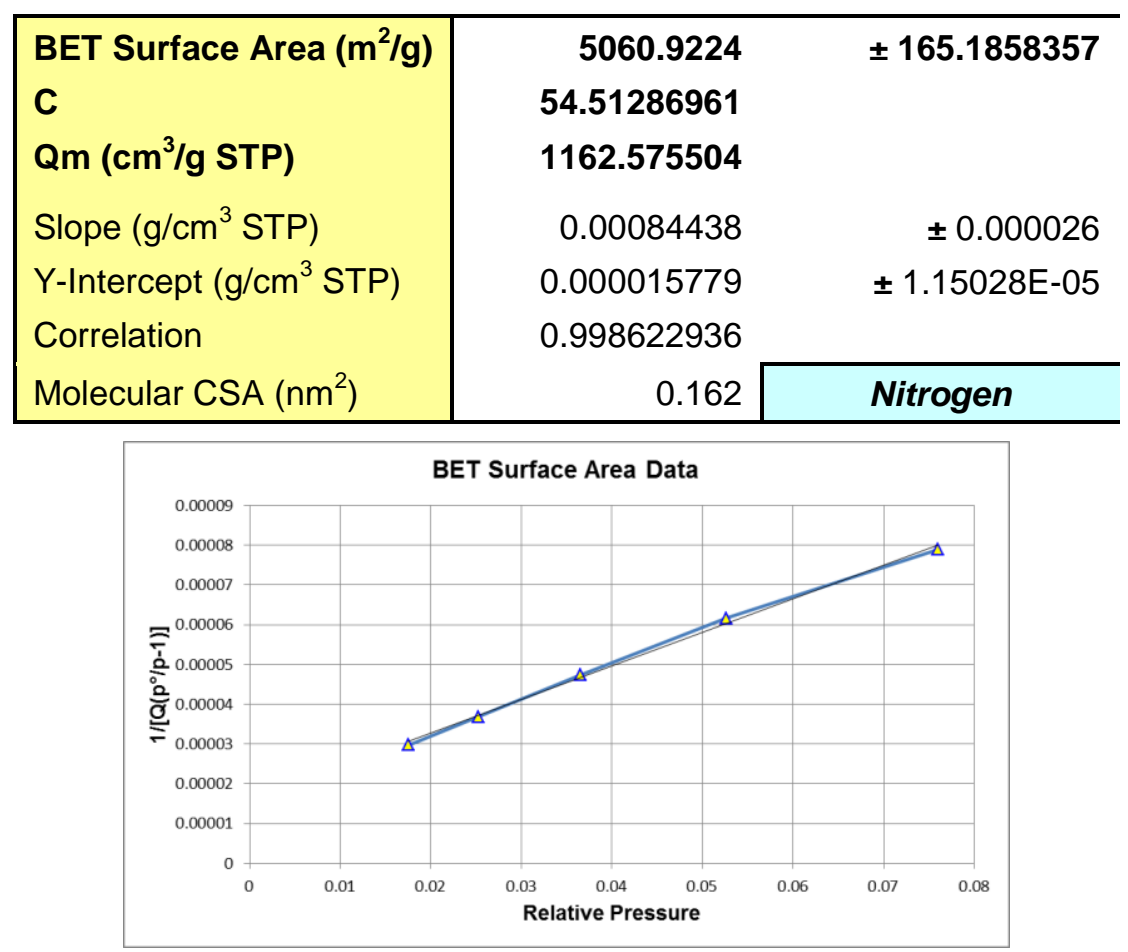

Figure S22. The fitting parameters and plot of the linear region for the BET equation for URMOF-4, which satisfies the first and second criterion for application of the BET theory. 


\section{Reference}

(S1) Sheldrick, G. M. Crystal structure refinement with SHELXL. Acta Crystallogr., Sect. C, 2015, $71,3-8$.

(S2) Spek, A. L. Single-crystal structure validation with the program PLATON. J. Appl. Crystallogr. 2003, 36, 7-13.

(S3) Xiang, S.; Zhou, W.; Gallegos, J. M.; Liu, Y.; Chen, B. Exceptionally High Acetylene Uptake in a Microporous Metal-Organic Framework with Open Metal Sites. J. Am. Chem. Soc. 2009, 131, 12415-12419.

(S4) Chen, B.; Eddaoudi, M.; Hyde, S. T.; O'Keeffe, M.; Yaghi, O. M. Interwoven metal-organic framework on a periodic minimal surface with extra-large pores. Science 2001, 291, 1021-1023.

(S5) Chae, H. K.; Siberio-Perez, D. Y.; Kim, J.; Go, Y.; Eddaoudi, M.; Matzger, A. J.; O'Keeffe, M.; Yaghi, O. M. A route to high surface area, porosity and inclusion of large molecules in crystals. Nature 2004, 427, 523-527.

(S6) Liu, Y.; Eubank, J. F.; Cairns, A. J.; Eckert, J.; Kravtsov, V.; Luebke, R.; Eddaoudi, M. Assembly of metal-organic frameworks (MOFs) based on indium-trimer building blocks: a porous MOF with soc topology and high hydrogen storage. Angew. Chem. Int. Ed. 2007, 46, 3278-3283.

(S7) Farha, O. K.; Özgür Yazaydın, A.; Eryazici, I.; Malliakas, C. D.; Hauser, B. G.; Kanatzidis, M. G.; Nguyen, S. T.; Snurr, R. Q.; Hupp, J. T. De novo synthesis of a metal-organic framework material featuring ultrahigh surface area and gas storage capacities. Nat. Chem. 2010, 2, 944-948. 
NMR Spectra
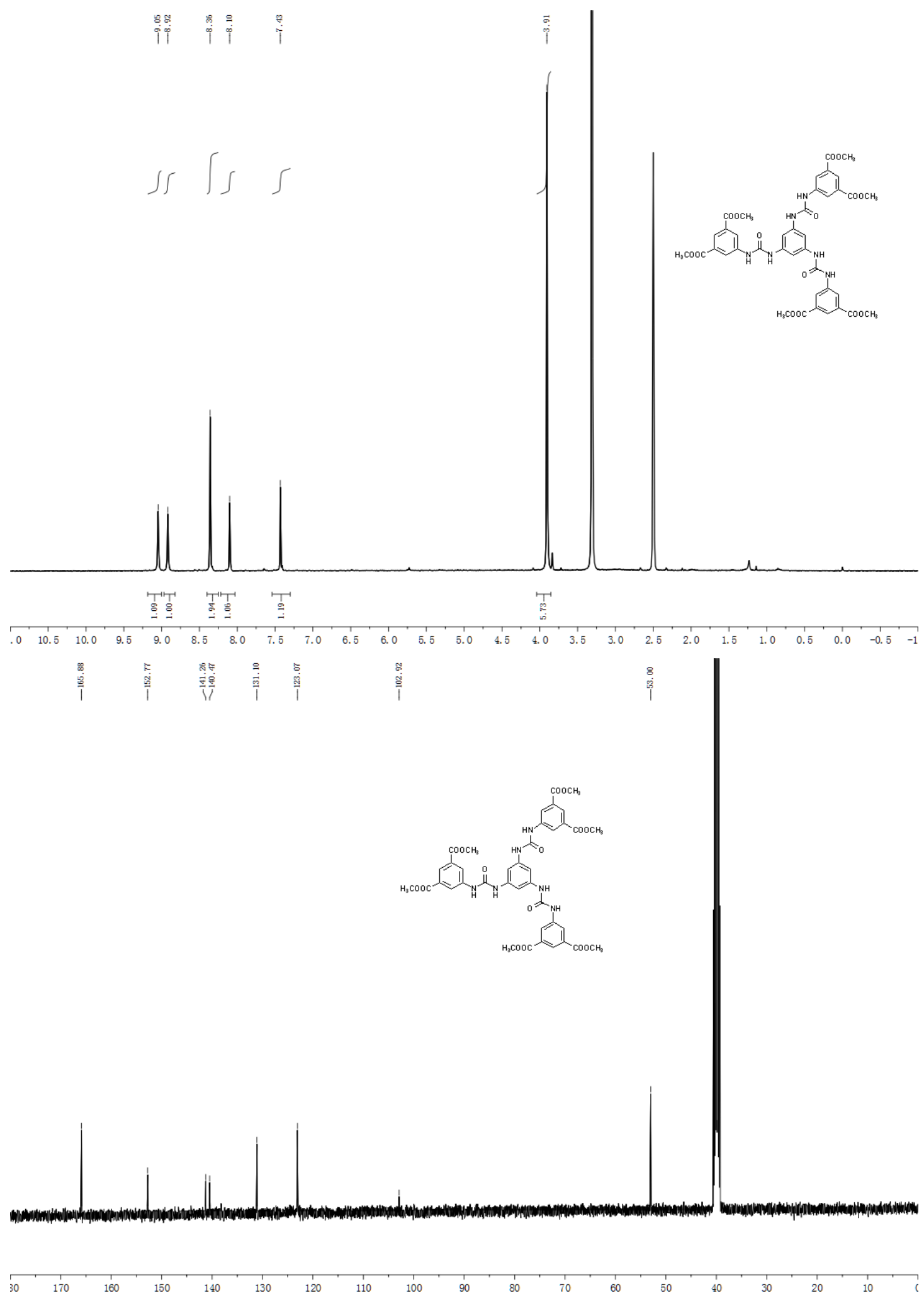

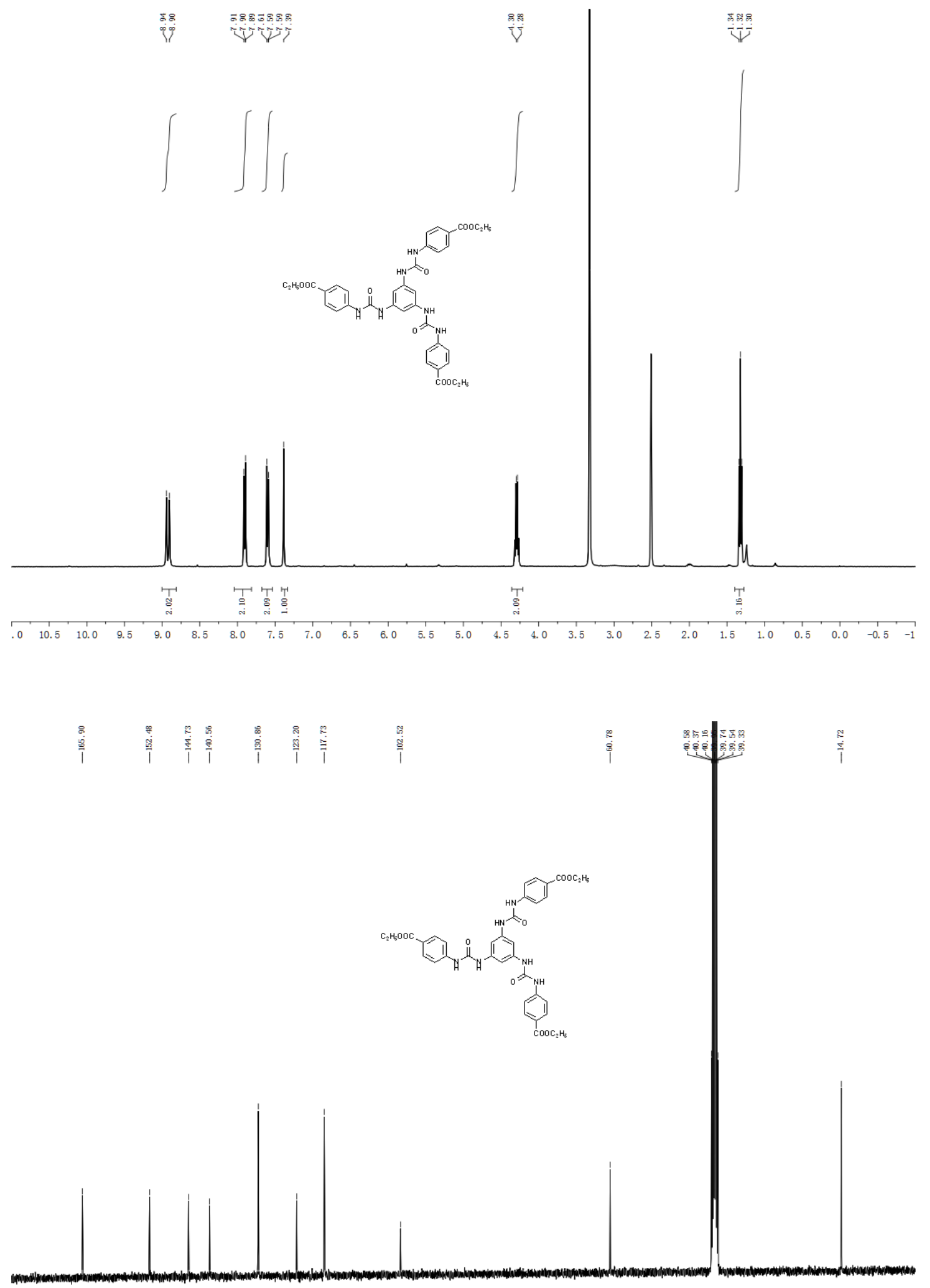

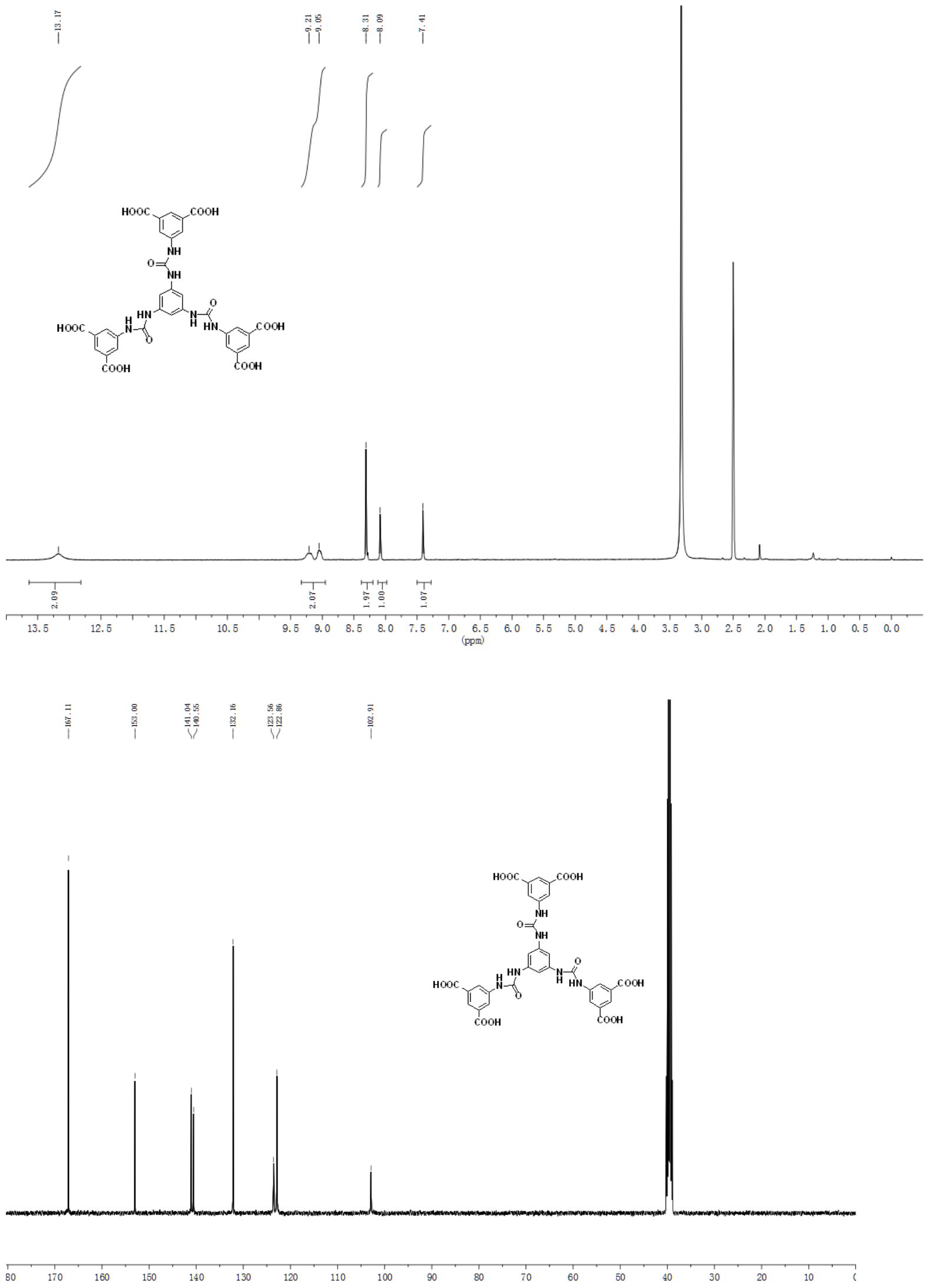

S27 

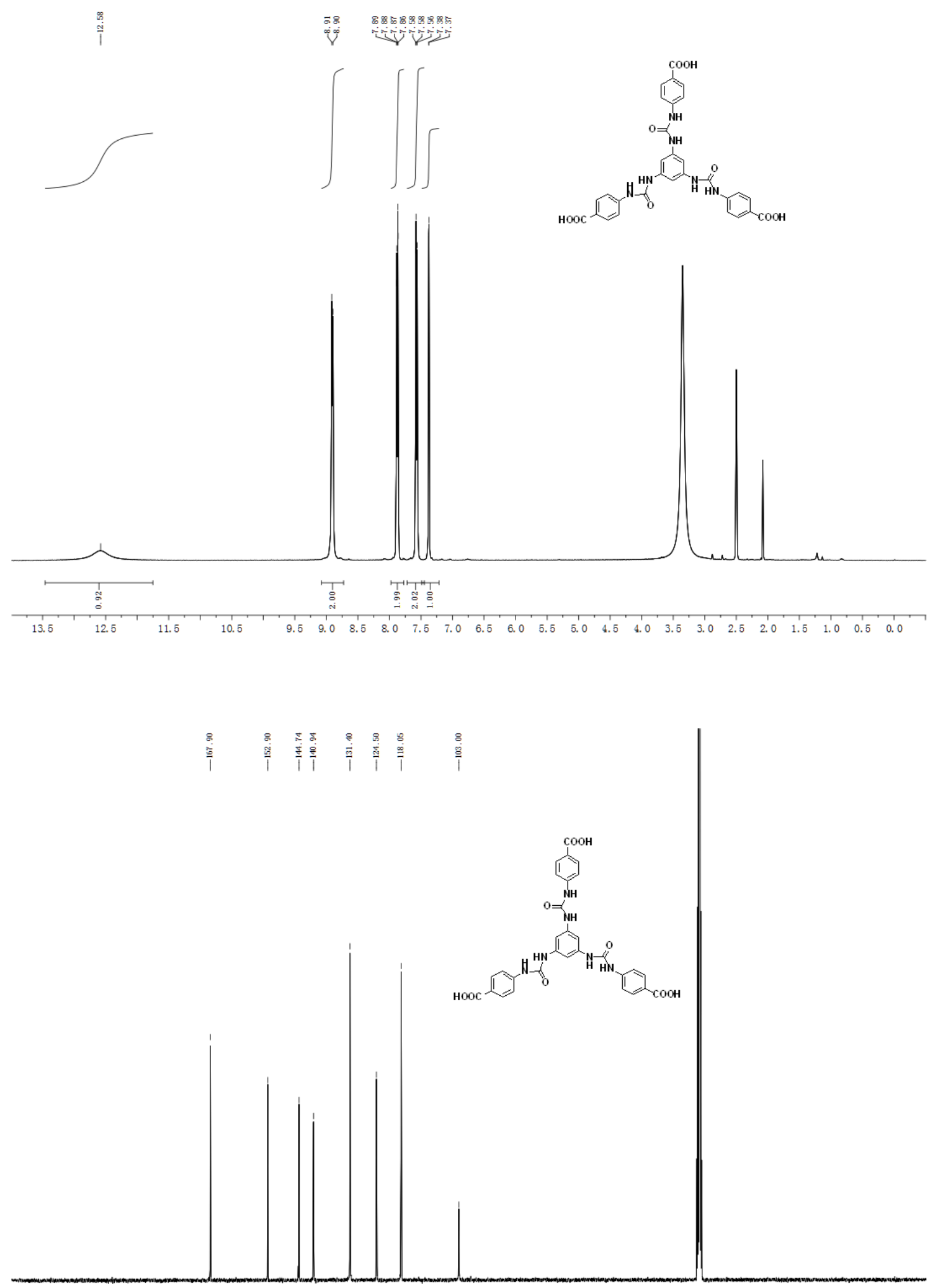


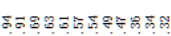

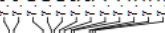

\|\|$\|$
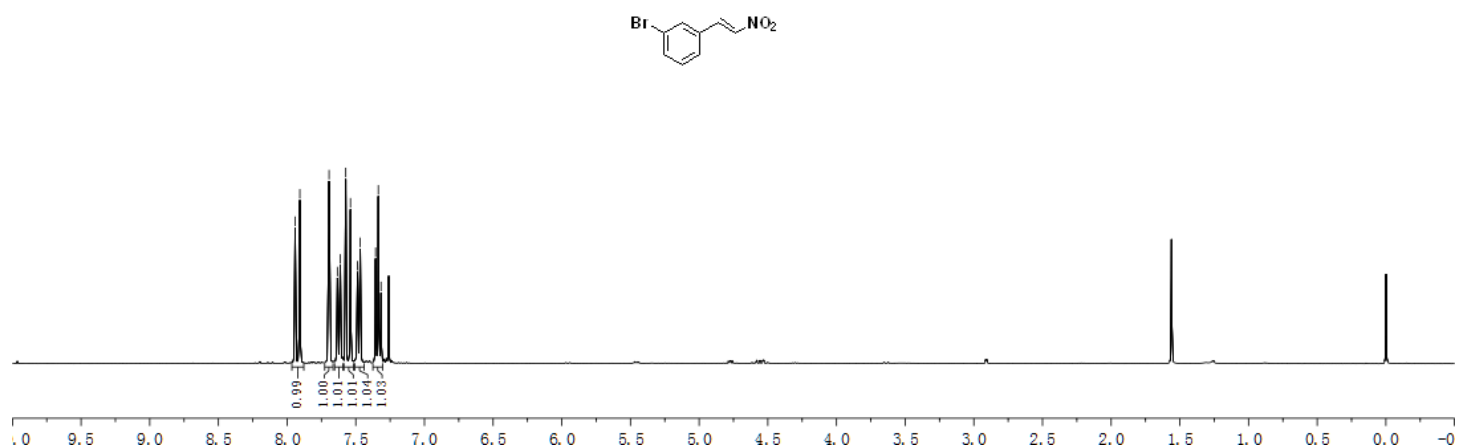

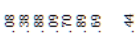

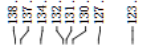

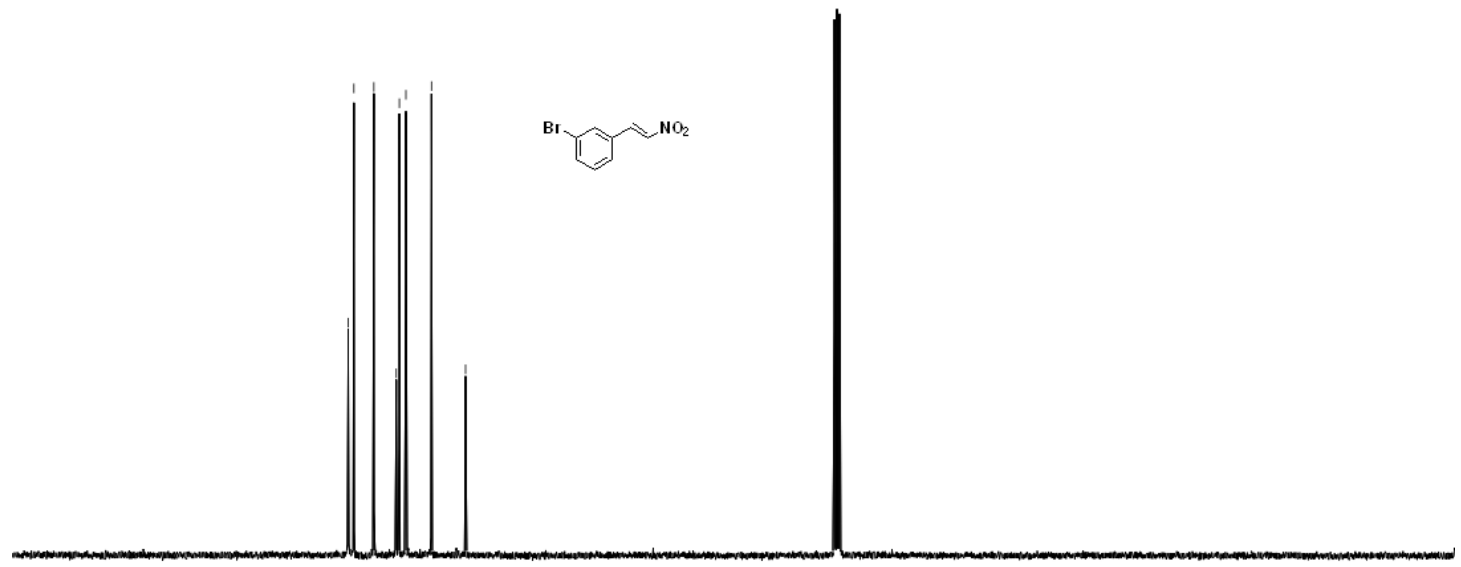



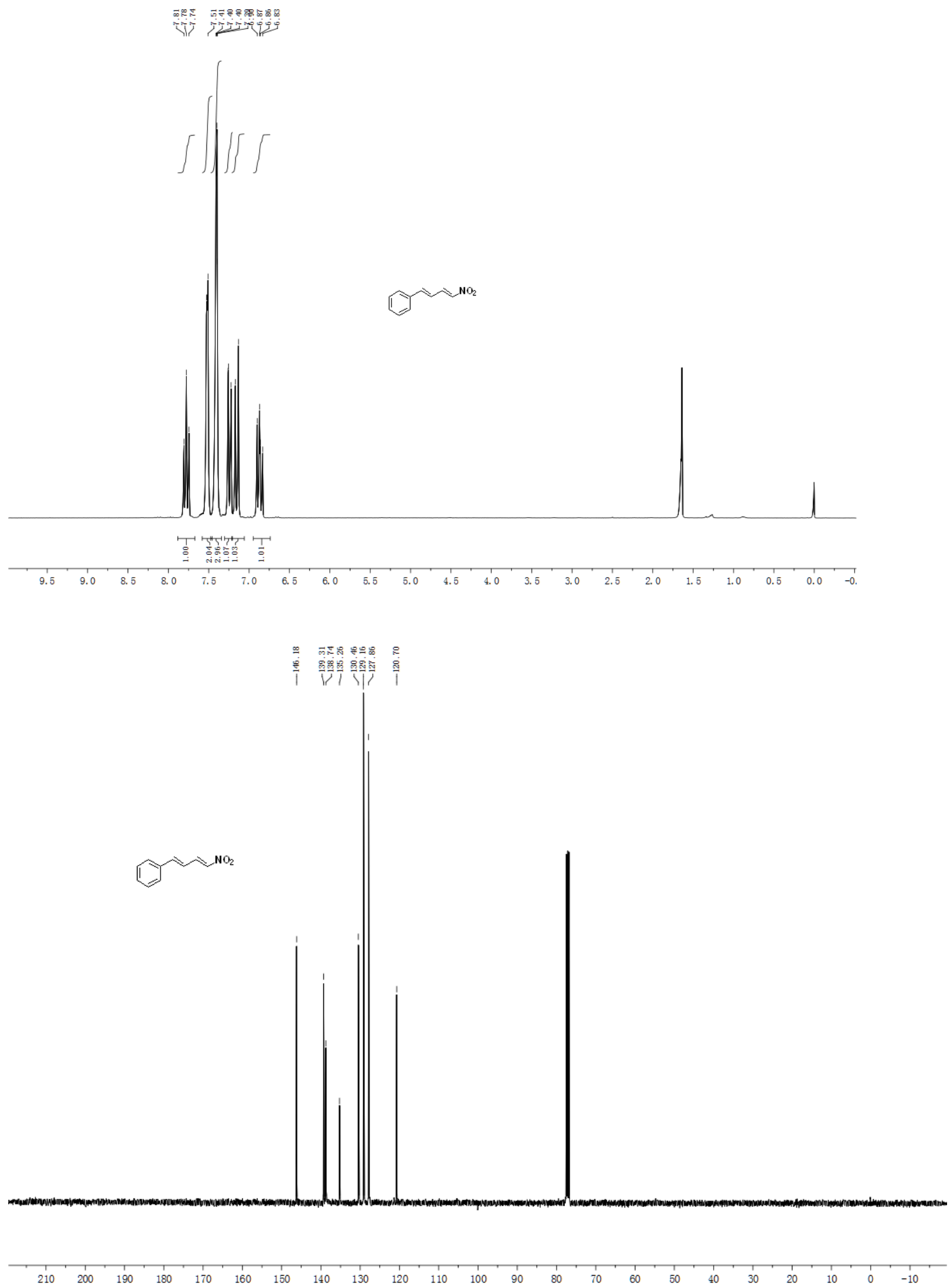


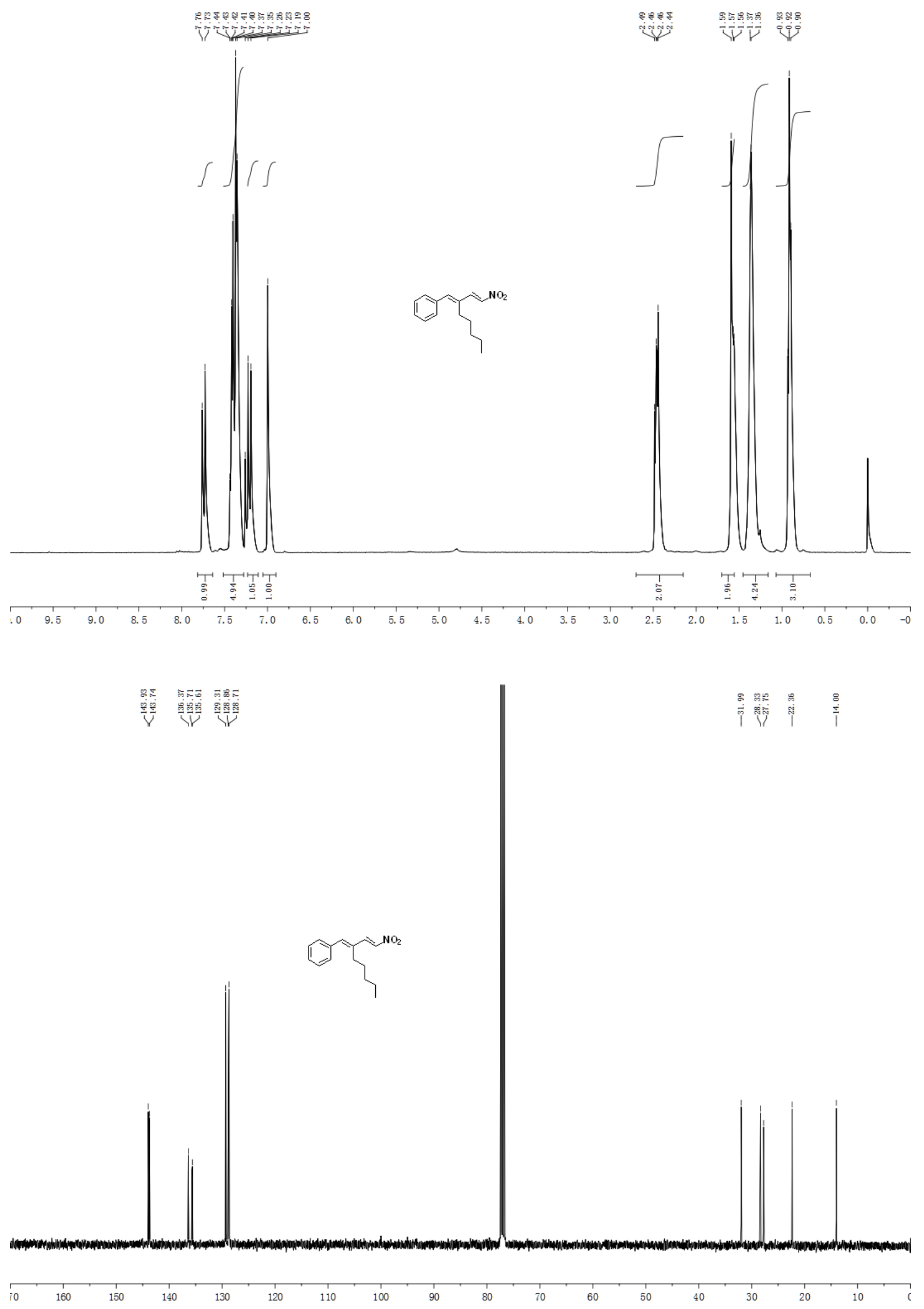



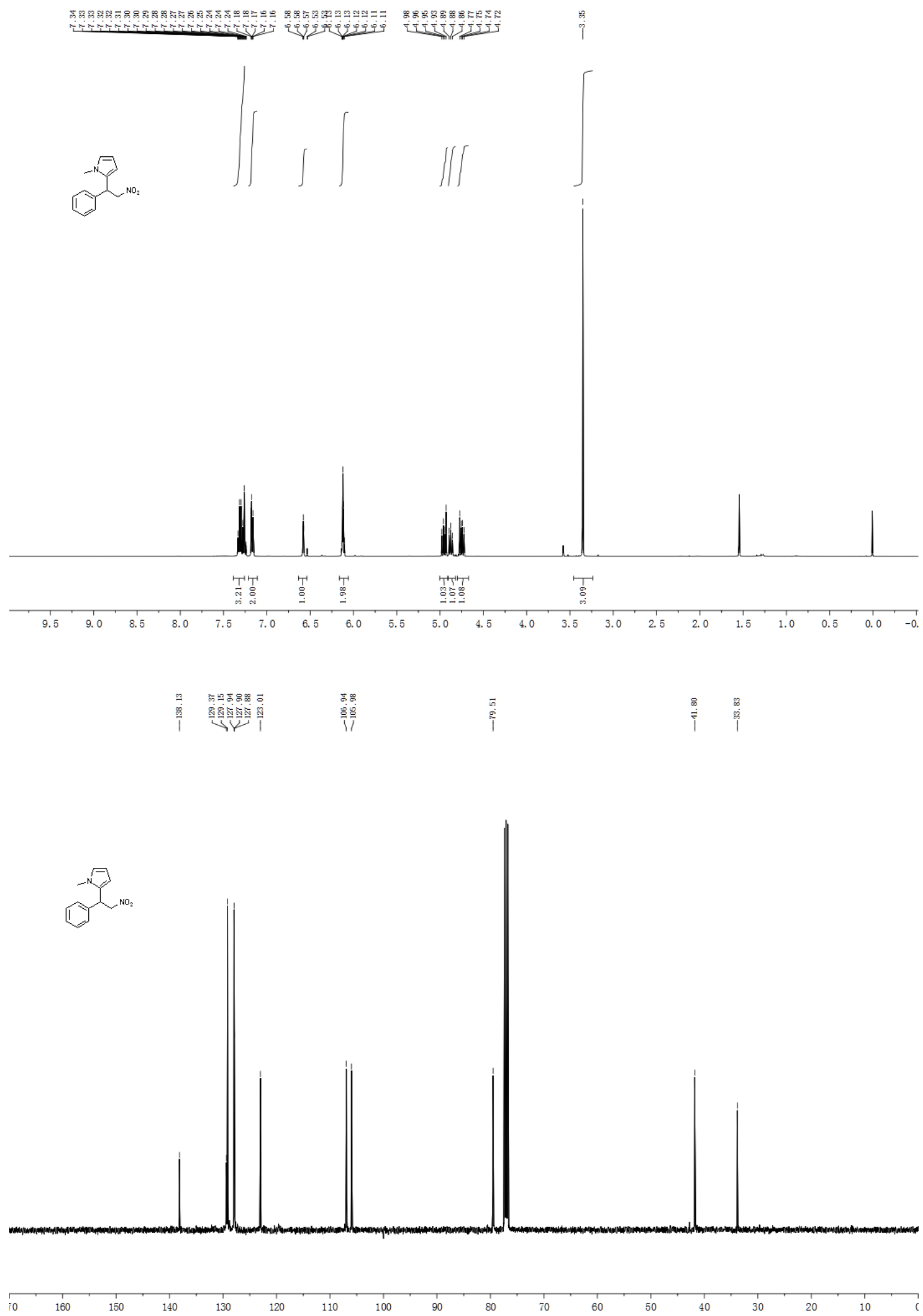

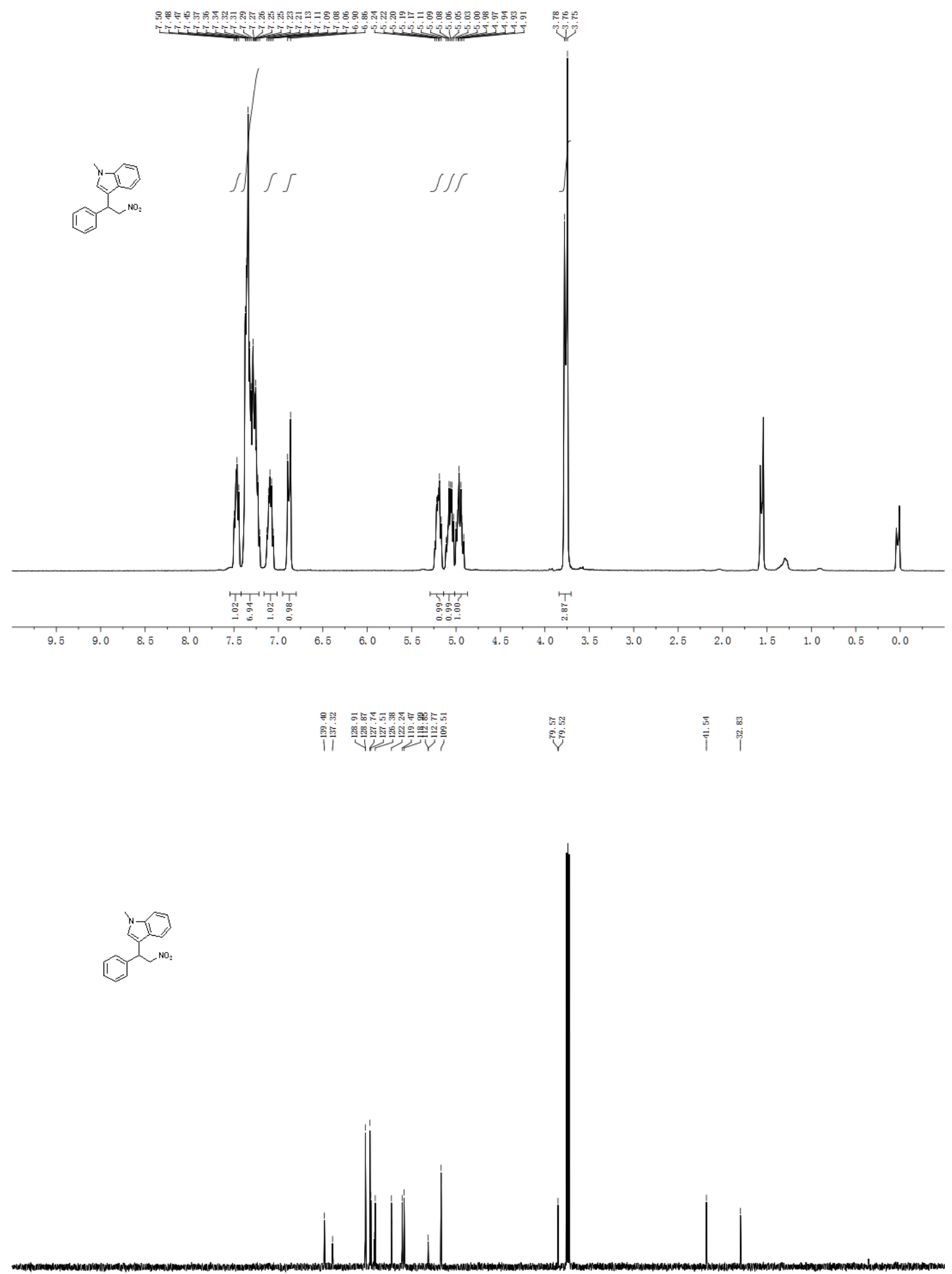


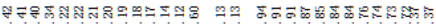

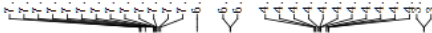

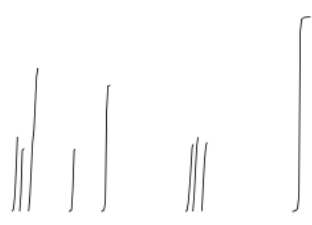

(1)

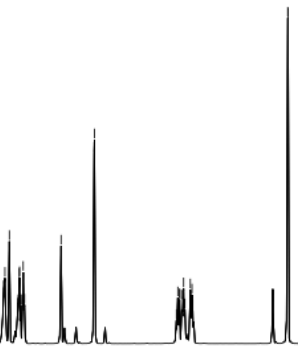

al.

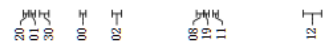

\begin{tabular}{|c|c|c|c|c|c|c|c|c|c|c|c|c|c|c|c|c|c|c|c|c|}
\hline 16 & 15 & 14 & 13 & 12 & 11 & 10 & 9 & 8 & 7 & 6 & 5 & 4 & 3 & 2 & 1 & 0 & -1 & -2 & -3 & -4 \\
\hline & & & 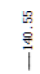 & & 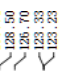 & & 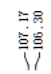 & & & & & & & & $\stackrel{\stackrel{\tilde{g}}{=}}{=}$ & 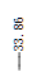 & & & & \\
\hline
\end{tabular}
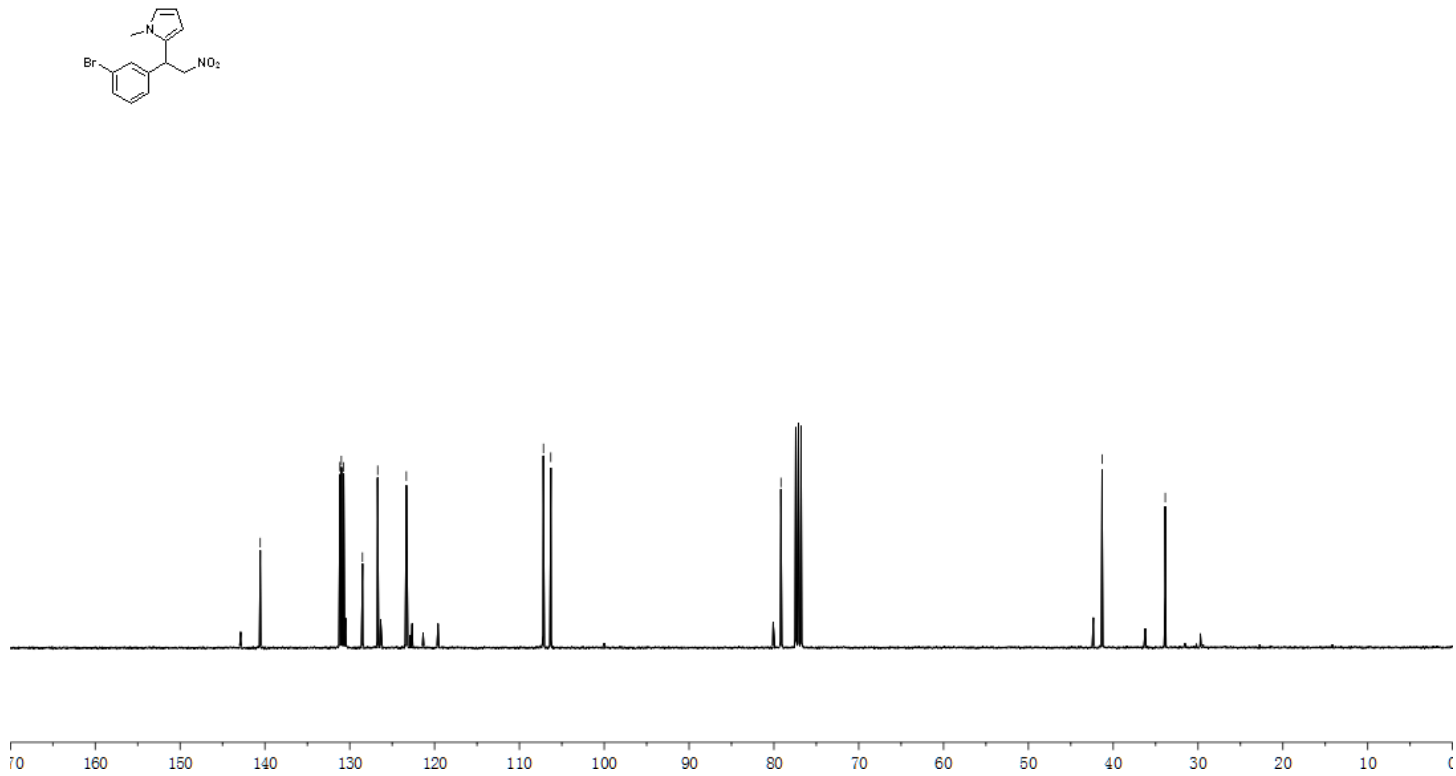

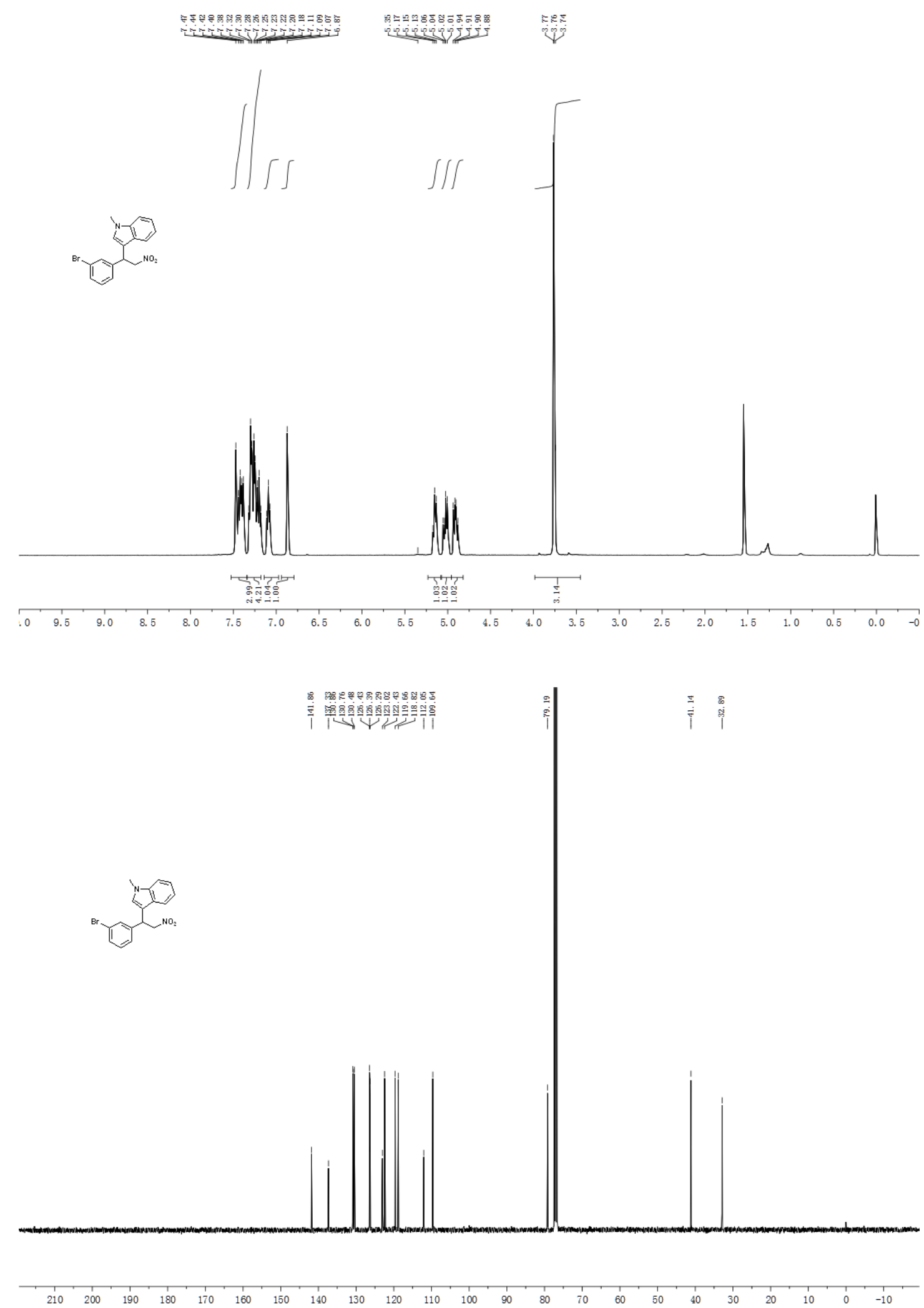

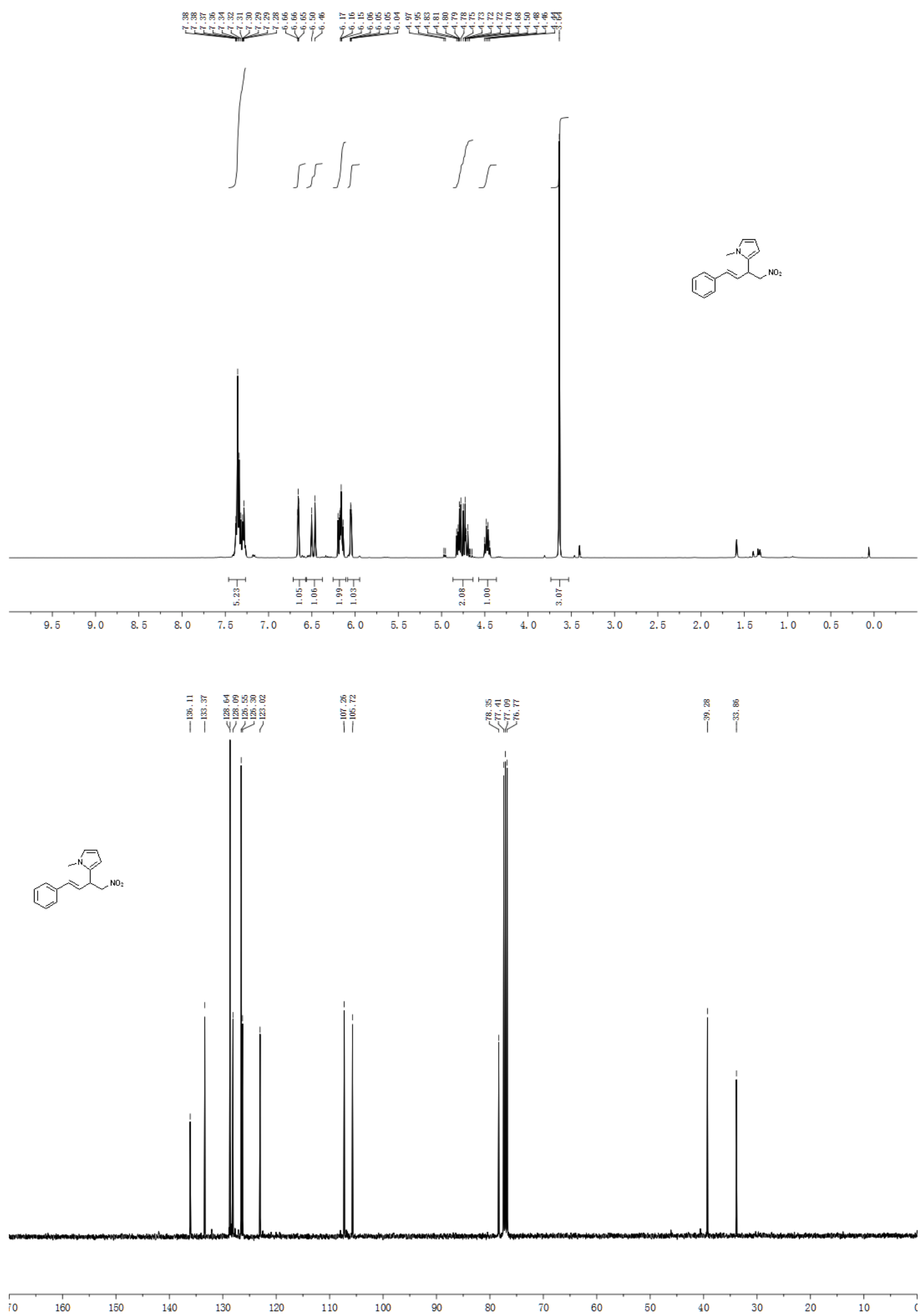

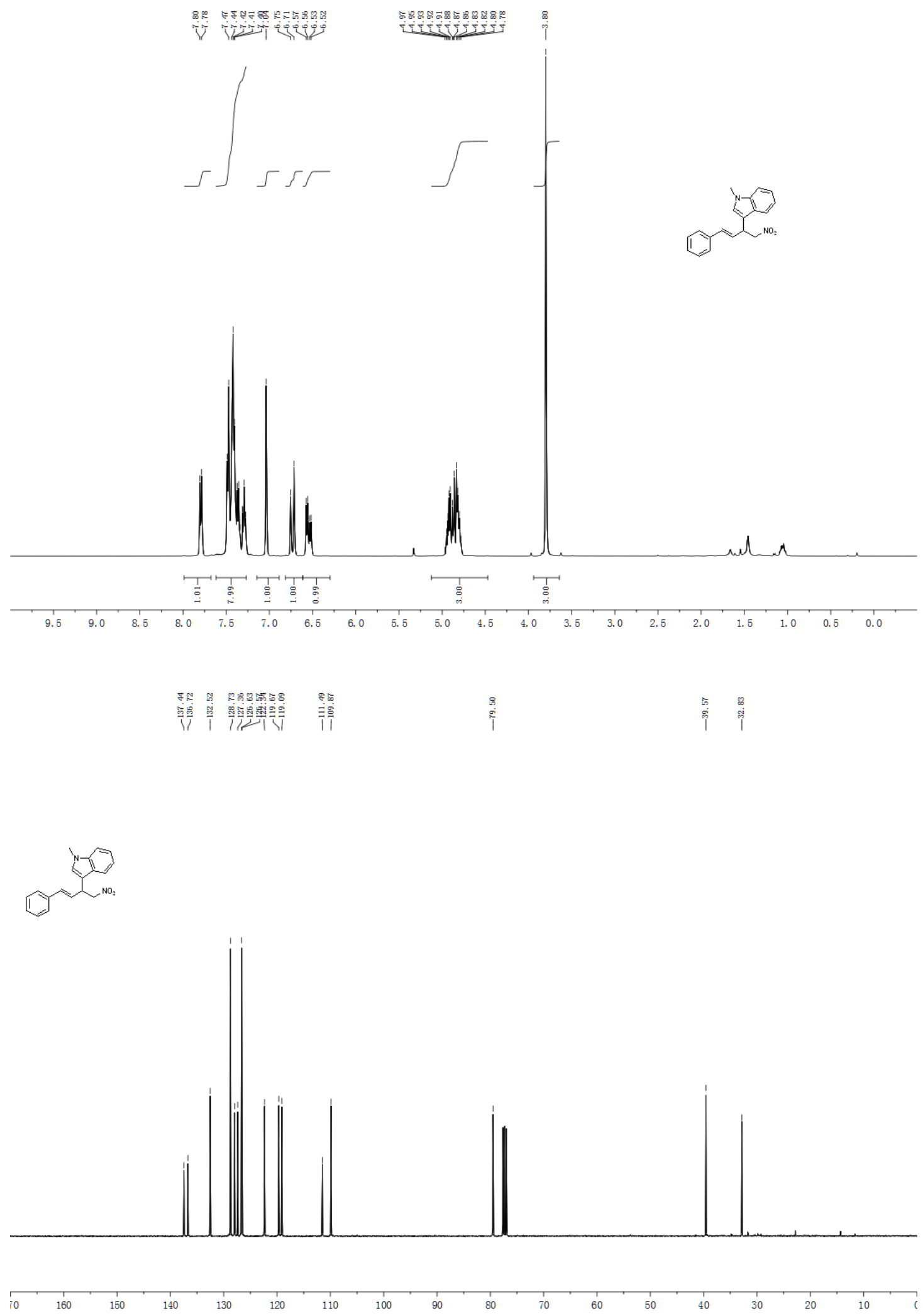

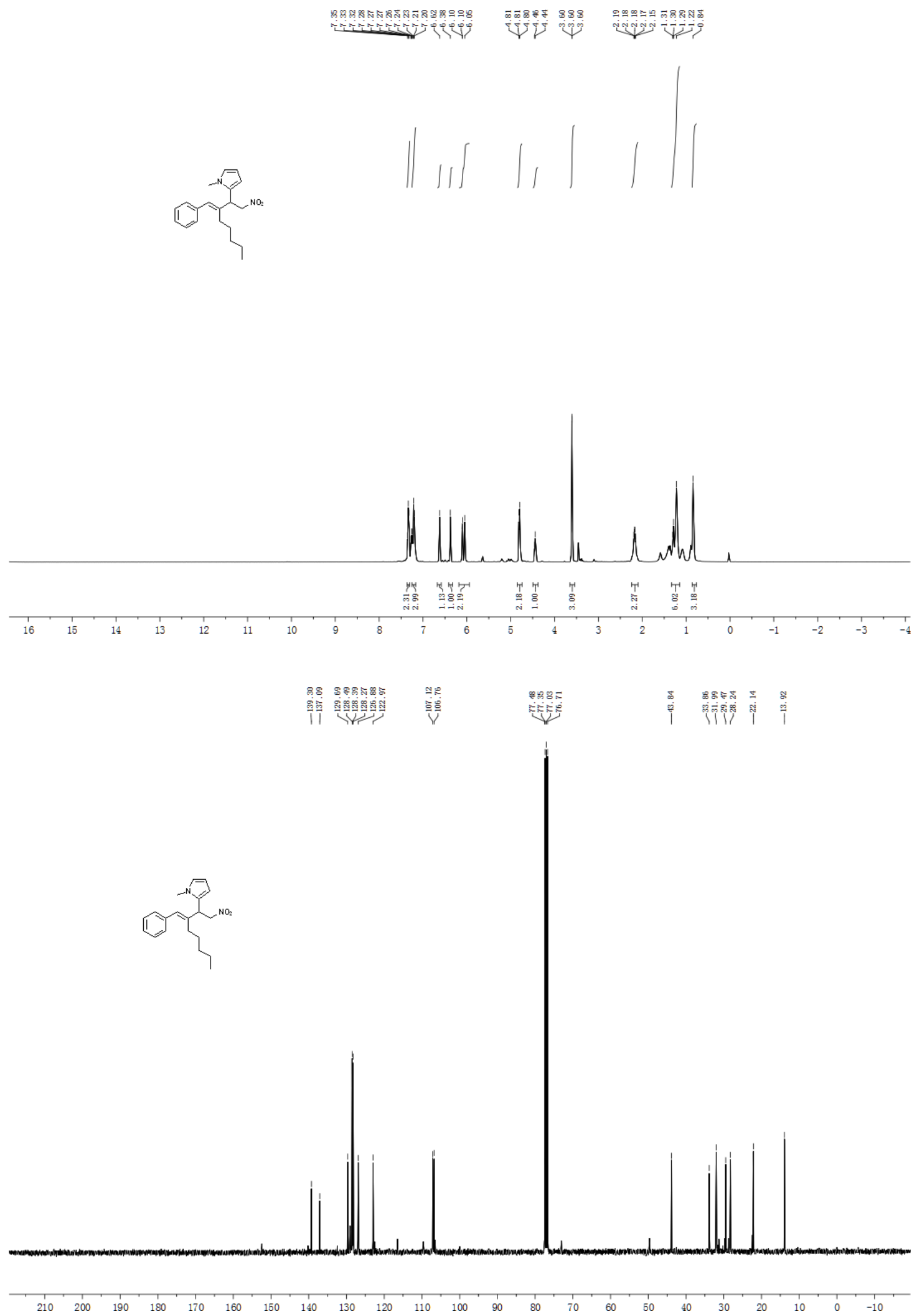

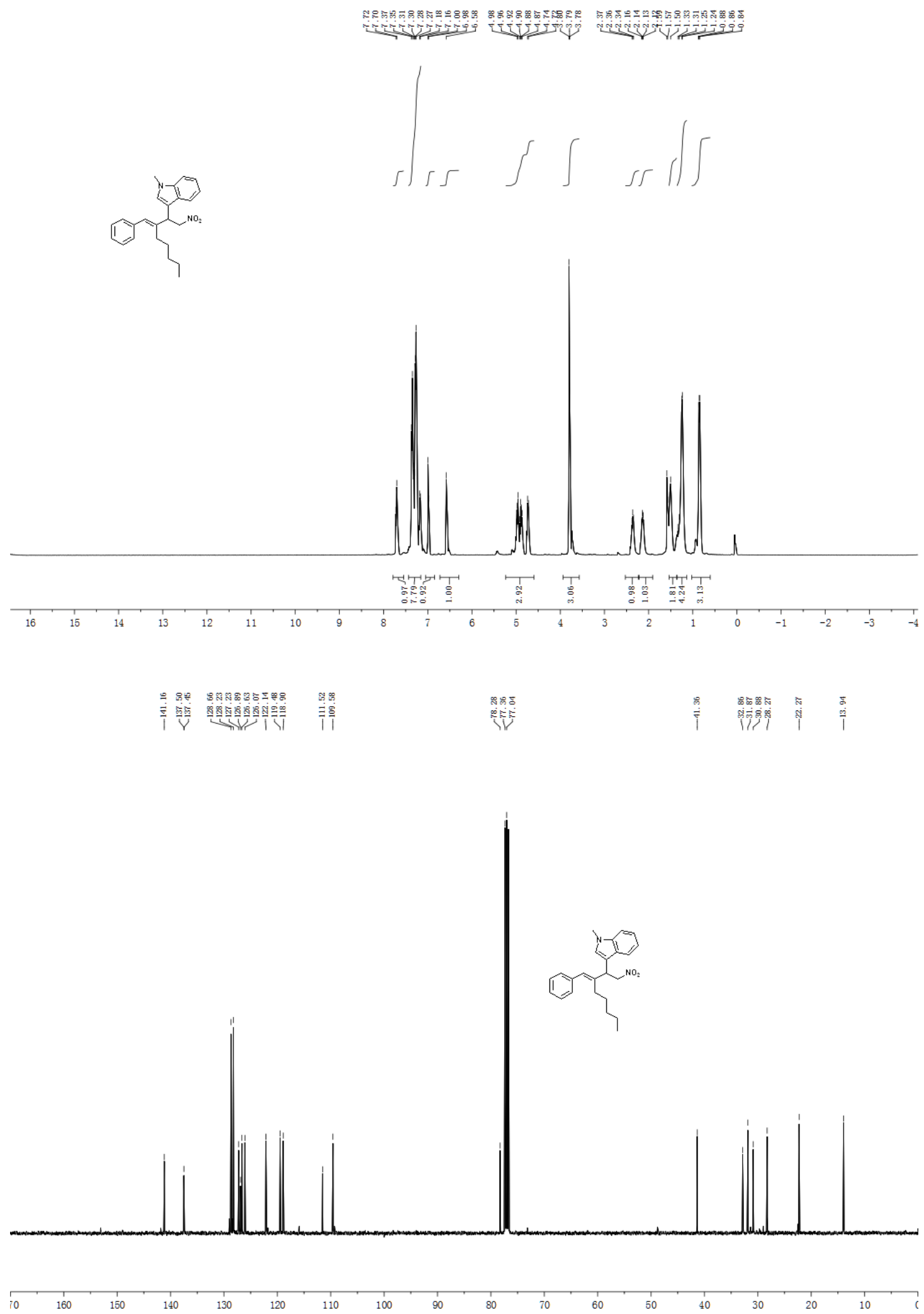